\title{
Genetic and Diet-Induced Obesity Increased Intestinal Tumorigenesis in the Double Mutant Mouse Model Multiple Intestinal Neoplasia X Obese via Disturbed Glucose Regulation and Inflammation
}

\author{
Ha Thi Ngo, Ragna Bogen Hetland, Unni Cecilie Nygaard, and Inger-Lise Steffensen \\ Department of Food, Water and Cosmetics, Division of Environmental Medicine, Norwegian Institute of Public Health, \\ P.O. Box 4404 Nydalen, 0403 Oslo, Norway
}

Correspondence should be addressed to Inger-Lise Steffensen; inger-lise.steffensen@fhi.no

Received 13 February 2015; Revised 17 June 2015; Accepted 8 July 2015

Academic Editor: B. J. Ammori

Copyright (C) $2015 \mathrm{Ha}$ Thi Ngo et al. This is an open access article distributed under the Creative Commons Attribution License, which permits unrestricted use, distribution, and reproduction in any medium, provided the original work is properly cited.

\begin{abstract}
We have studied how spontaneous or carcinogen-induced intestinal tumorigenesis was affected by genetic or diet-induced obesity in C57BL/6J-Apc $c^{\mathrm{Min} /+}$ X C57BL/6J-Lep $p^{o b /+}$ mice. Obesity was induced by the obese (ob) mutation in the lep gene coding for the hormone leptin, or by a $45 \%$ fat diet. The effects of obesity were examined on spontaneous intestinal tumors caused by the multiple intestinal neoplasia (Min) mutation in the adenomatous polyposis coli (Apc) gene and on tumors induced by the dietary carcinogen 2-amino-1-methyl-6-phenylimidazo[4,5-b] pyridine (PhIP). F1 ob/ob (homozygous mutated) mice had increased body weight (bw) and number of spontaneous and PhIP-induced small intestinal tumors (in $A p c^{M i n /+}$ mice), versus ob/wt (heterozygous mutated) and wt/wt mice (homozygous wild-type). A $45 \%$ fat diet exacerbated bw and spontaneous tumor numbers versus $10 \%$ fat, but not PhIP-induced tumors. Except for bw, ob/wt and wt/wt were not significantly different. The obesity caused hyperglucosemia and insulinemia in ob/ob mice. A $45 \%$ fat diet further increased glucose, but not insulin. Inflammation was seen as increased TNF $\alpha$ levels in ob/ob mice. Thus the results implicate disturbed glucose regulation and inflammation as mechanisms involved in the association between obesity and intestinal tumorigenesis. Ob/ob mice had shorter lifespan than ob/wt and wt/wt mice.
\end{abstract}

\section{Introduction}

Obesity is defined as an excess accumulation of adipose tissue. The rate of obesity has more than doubled over the past 20 years in most OECD countries [1]. More than half of the adult population are overweight (with body mass index (BMI) $25-29.9 \mathrm{~kg} / \mathrm{m}^{2}$ ) or obese (with BMI $\geq 30 \mathrm{~kg} / \mathrm{m}^{2}$ ), and about $18 \%$ of both genders are obese. Rates of overweight and obesity among children are also increasing; average reported overweight rates (including obesity) increased from 13\% in 2001-2002 to 15\% in 2009-2010 for 15-year-olds (based on ageand gender-specific cut-off points for BMI) [1].

A parallel increase in overweight/obesity and many forms of cancer has been observed in most countries around the world in the past two to three decades. Cancer is now the second leading cause of mortality in the OECD countries [1]. In Norway, colon cancer is the second most prevalent cancer for women, after breast cancer, and the third most prevalent cancer for men, after prostate and lung cancer [2]. In the experiment described in this paper, we have examined how obesity may affect intestinal tumorigen-esis.

Obesity alters the physiology of the whole organism, and therefore animal models are required to study the effects of increased adiposity. In addition, models that integrate lifestyle and genetic factors in a single model system provide a physiologically intact system valuable for studies of complex relationships. In the present work, we have studied the relationship between obesity and intestinal tumorigenesis in the double-mutant F1 offspring obtained by crossing a mouse 
model for intestinal tumorigenesis and a mouse model for obesity.

The well-established model for intestinal tumorigenesis, the C57BL/6J-Apc $c^{\mathrm{Min} /+}$ mouse, is heterozygous for the germline nonsense mutation multiple intestinal neoplasia (Min) in the tumor suppressor gene adenomatous polyposis coli $(A p c)$ leading to a truncated nonfunctional APC protein, and therefore develops numerous spontaneous intestinal tumors [3,4]. Apc is a key component in the Winglessrelated integration site (Wnt) signaling pathway $[5,6]$. The Min mouse is a model for the inherited disorder familial adenomatous polyposis (FAP), as well as for sporadic colorectal cancer in humans $[7,8]$, and develops multiple adenomas in the small intestine and to a much lesser degree in the colon.

The Min mouse was crossed with the C57BL/6J-Lep ${ }^{o b /+}$ mouse, heterozygous for the obese $(o b)$ mutation in the leptin (lep) gene, which becomes obese when having a homozygous mutation $(o b / o b)$ and therefore lacks functional leptin hormone [9-11]. In addition to being obese, the ob/ob mice are reported to exhibit hyperphagia, a transient diabetes-like syndrome of hyperglycemia, glucose intolerance, elevated plasma insulin, subfertility, impaired wound healing, and increased hormone production from pituitary and adrenal glands, and apparently they are hypometabolic and hypothermic [12]. Leptin regulates food intake and energy expenditure and has effects on immune functions, including inflammation, and reproduction $[11,13]$.

Obesity is caused by an imbalance between caloric intake and energy expenditure, which is influenced by both genetic and environmental factors. In this work, we have used two models for obesity. By studying obesity induced genetically in the $o b$ mouse, we could examine the effect of obesity on intestinal tumorigenesis independent of diet. In addition, we studied environmentally-induced obesity, that is, dietinduced obesity (DIO), by giving the F1 mice either a $45 \%$ fat diet or a control $10 \%$ fat diet as adults (from weaning to termination).

In addition to the effects on spontaneous intestinal tumors caused by the inherited mutated $A p c$ gene in the $\mathrm{Min} /+$ mice, the effect of obesity was also examined on tumors induced by the environmental (dietary) factor formed during cooking of meat and fish, the mutagenic, genotoxic and carcinogenic heterocyclic amine 2-amino-1-methyl-6phenylimidazo[4,5-b]pyridine (PhIP) [14]. Previously, we have reported that PhIP increased intestinal tumorigenesis in adult C57BL/6J-Min/+ mice [15] and that the Min/+ mice were much more susceptible to PhIP if exposed neonatally $[16,17]$ than as young adults $[15,17]$.

In this work, we have studied obesity as an end point in itself, and as a factor impacting on intestinal tumorigenesis. The obesity was either caused genetically by the inherited $o b$ mutation or environmentally by a $45 \%$ fat diet. We examined whether genetically-or diet-induced obesity increased spontaneous or carcinogen-induced intestinal tumorigenesis in the Min X $o b$ mice. Furthermore, we examined two hypotheses for the relationship between obesity and intestinal tumorigenesis: disturbed blood glucose regulation and increased inflammation. In addition, we have examined the impact of heterozygous or homozygous $o b$ mutation on long-term survival of mice with or without mutated $A p c$ gene.

\section{Materials and Methods}

2.1. Mice. The Min (multiple intestinal neoplasia) pedigree was bred at The Norwegian Institute of Public Health, Oslo, Norway, by mating C57BL/6J-Apc $\mathrm{C}^{+/+}$(B6J, wild-type) females with C57BL/6J-Apc $c^{M i n /+} / \mathrm{J}$ (stock 002020) males purchased from The Jackson Laboratory (Bar Harbor, ME, USA). To minimize the genetic drift away from the colony at the Jackson Laboratory, both females and males in the breeding stock at our institute were replaced regularly. Mice with the obese (ob) mutation in the leptin (lep) gene, B6.V-Lep ${ }^{o b /+} / \mathrm{J}$ (stock 000632), were also purchased from The Jackson Laboratory.

2.2. Experimental Groups. In total, 48 experimental groups were included in this experiment: 6 genotypes $\left(A p c^{+++} X\right.$ $L e p^{w t / w t}, A p c^{+/+} X L e p^{o b / w t}, A p c^{+/+} X L e p^{o b / o b}, A p c^{M i n /+} \times$ $L e p^{w t / w t}, A p c^{M i n /+} \times L e p^{o b / w t}$, or $\left.A p c^{M i n /+} \times L e p^{o b / o b}\right) \times 2$ genders (females or males) $\times 2$ treatments $(0.9 \% \mathrm{NaCl}$ or PhIP) $\times 2$ diets (a $10 \%$ fat or a $45 \%$ fat diet). Homozygous mutant $A p c^{\mathrm{Min} / \mathrm{Min}}$ mice die during the embryo stages [18], whereas homozygous Lep ${ }^{o b / o b}\left(o b^{-/-}\right)$mice are viable $[9,11]$. The Min mutation was propagated through males to avoid that the resulting intestinal adenomas and anemia might interfere with pregnancy in females [3]. Mice with leptindeficiency (genetically induced obesity), that is, the Lep ${ }^{o b / o b}$ mice, were used to study the effects of obesity separated from the influence of diet. Six genotype combinations were obtainable from crosses between Min mice and $o b$ mice, via two generations. First, $A p c^{+/+}{\mathrm{X} o b^{+/-}}$females and $A p c^{\mathrm{Min} /+} \mathrm{X}$ $o b^{+/+}$males were crossed. Then the mice that were included in the experimental groups were produced by crossing of $A p c^{+/+}$ $\mathrm{X} o b^{+/-}$females and $A p c^{\mathrm{Min} /+} X o b^{+/-}$males. To separate the wild-type (normal, nonmutated) allele of the $o b$ gene from the wild-type allele of the $A p c$ gene, throughout this paper the wild-type allele of the $o b$ gene is designated "wt", whereas the wild-type allele of Apc is designated "+." The three $o b$ genotypes obtained were wt/wt (homozygous wildtype), ob/wt (heterozygous mutated) and ob/ob (homozygous mutated), and the two Apc genotypes obtained were +/+ (homozygous wild-type) and Min/+ (heterozygous mutated).

Breeding of the experimental mice continued until approximately 11 mice per experimental group were obtained (number based on power analysis and experience with this model); however, to achieve this some groups ended up with higher numbers. The number of mice $(n)$ per treatment group is given in the text and in figure legends and tables, for each end point.

2.3. Genotyping, Housing and Termination of the Mice. All Min X ob F1 offspring were genotyped for both Min and $o b$ status by allele-specific polymerase chain reaction (PCR) analysis. DNA was extracted from $\sim 2 \mathrm{~mm}^{2}$ samples obtained 
by ear puncture for identification of individual mice at weaning and kept on ice. The samples were suspended in $60 \mu \mathrm{L}$ TE-buffer with sodium dodecyl sulfate (SDS) $(10 \mathrm{mM}$ Tris pH 7.4, 0.1 mM EDTA pH 8.0, 0.05\% SDS) and incubated at $95^{\circ} \mathrm{C}$ for $10 \mathrm{~min}$. Then aliquots of $6 \mu \mathrm{L}$ of $10 \mathrm{mg} / \mathrm{mL}$ Proteinase K (Sigma-Aldrich Corp., St. Louis, MO, USA) were added and the samples incubated at $56^{\circ} \mathrm{C}$ overnight. Finally, the samples were incubated at $95^{\circ} \mathrm{C}$ for $10 \mathrm{~min}$ to inactivate the enzyme and stored at $-20^{\circ} \mathrm{C}$ until PCR amplification. The PCR reactions for genotyping of $A p c$ status were carried out as described previously [19]. For ob genotyping, the PCR reactions were carried out on an Eppendorf Mastercycler gradient (Eppendorf AG, Hamburg, Germany) as follows. Genomic DNA ( $5 \mu \mathrm{L}$ of $1: 100$ dilution of isolated DNA) was amplified in a $10 \mu \mathrm{L}$ reaction volume per sample, which contained final primer concentrations of $0.9 \mu \mathrm{M}$ of each of the following primers: oIMR1151 (5' -TGTCCAAGATGGACCAGACTC$\left.3^{\prime}\right)$ and oIMR1152 (5'-ACTGGTCTGAGGCAGGGAGCA$3^{\prime}$ ), purchased from Eurogentec s.a. (Seraing, Belgium), $0.2 \mu \mathrm{M}$ of dCTP, dGTP, dTTP, and dATP (Promega Corp., Madison, WI, USA), 1x DyNazyme II Hot Start Reaction buffer (15 mM Tris- $\mathrm{HCl}$ (pH 8.2), $30 \mathrm{mM} \mathrm{KCl,} 2.5 \mathrm{mM} \mathrm{Mg}{ }^{2+}$, $5 \mathrm{mM}\left(\mathrm{NH}_{4}\right) \mathrm{SO}_{4}$ and $0.02 \%$ bovine serum albumin (BSA)), and $0.008 \mathrm{U} / \mu \mathrm{L}$ DyNazyme II Hot Start DNA polymerase (both from Thermo Fischer Scientific Inc., Waltham, MA, USA). The amplification conditions were $10 \mathrm{~min}$ at $94^{\circ} \mathrm{C}$ before 35 cycles at $94^{\circ} \mathrm{C}$ for $15 \mathrm{sec}, 64^{\circ} \mathrm{C}$ for $30 \mathrm{sec}$ and $72^{\circ} \mathrm{C}$ for $23 \mathrm{sec}$, followed by a final extension at $72^{\circ} \mathrm{C}$ for $5 \mathrm{~min}$. After the PCR amplification, $10 \mu \mathrm{L}$ PCR products and $5 \mu \mathrm{L}$ restriction enzyme mix, which in the final concentration of $15 \mu \mathrm{L}$ volume contained $0.56 \mathrm{x}$ buffer $\mathrm{D}, 0.06 \mathrm{mg} / \mathrm{mL}$ BSA and $0.23 \mathrm{U}$ Dde I enzyme (Promega Corp.), were incubated for $12 \mathrm{~h}$. The PCR products were visualized by electrophoresis through a $2.2 \%$ agarose gel (Lonza FlashGel system, Lonza, Basel, Switzerland). The wild-type (wt/wt) mice were identified as having a $155 \mathrm{bp}$ PCR product, the heterozygous mutated (ob/wt) mice with the $155 \mathrm{bp}$, a $100 \mathrm{bp}$ and a $55 \mathrm{bp}$ PCR product, and the homozygous mutated (ob/ob) mice as having a $100 \mathrm{bp}$ and a $55 \mathrm{bp}$ PCR product. The reagents were purchased from Sigma-Aldrich Corp. (St. Louis, MO, USA), Fluka (Buchs SG, Switzerland) and Promega Corp. (Madison, WI, USA), if not stated otherwise.

The littermates of the same gender were housed up to 5 mice per cage in $100 \%$ PET plastic disposable cages on Nestpak Aspen 4HK bedding (Datesand Ltd., Manchester, UK) in air flow IVC racks (Innovive Inc., San Diego, CA, USA). The room had 12-h light/dark cycle and controlled humidity $(55 \pm 5 \%)$ and temperature $\left(20-24^{\circ} \mathrm{C}\right)$. Water and feed were given ad libitum to all mice.

The mice in the experimental groups were terminated at 11 weeks of age, before onset of noticeable anemia caused by their tumors. Blood was sampled by cardiac puncture under anesthesia with ZRF cocktail (containing $3.3 \mathrm{mg}$ zolazepam, $3.3 \mathrm{mg}$ tiletamine, $0.5 \mathrm{mg}$ xylazine and $2.6 \mu \mathrm{g}$ fentanyl per $\mathrm{mL} 0.9 \% \mathrm{NaCl}$ ) into Microvette Lithium Heparin tubes for plasma from Sarstedt AS (Ski, Norway) for cytokine and hormone analyses. Thereafter, the mice were sacrificed by cervical dislocation.
2.4. Ethics Statement. The study was performed in strict accordance with the laws and regulations for animal experiments in Norway. The protocols were approved by the Norwegian Animal Research Authority (NARA) (permit numbers 1357 and 4856). Cardiac puncture and cervical dislocation were performed under ZRF cocktail anesthesia, before dissection of organs after death. Every effort was made to minimize suffering.

2.5. Dietary Carcinogen. 2-Amino-1-methyl-6-phenylimidazo $[4,5 b]$ pyridine hydrochloride (PhIP-HCl) (CAS no. 105650-23-5), Cat. no. 163-15951, of $>99 \%$ purity was purchased from Wako Chemicals GmbH (Neuss, Germany). $\mathrm{PhIP}-\mathrm{HCl}$ was dissolved in distilled water, and the $\mathrm{pH}$ was adjusted to approximately 4.0 .

2.6. Breeding and Experimental Diets. The breeding pairs, as well as their offspring until weaning at three weeks of age, were fed a breeding diet, 2018 Teklad Global 18\% Protein Rodent Diet from Harlan Industries Inc. (Indianapolis, IN, USA). The mice bred for obtaining breeding pairs, not included in the experimental groups, were given a standard maintenance diet, SDS RM1 (E) from SDS Special Diets Services (Essex, UK), after weaning.

In addition to genetically-induced obesity caused by the $o b$ mutation, we also studied the effects of diet-induced obesity (DIO), more relevant to the obese condition in most humans. Approximately every other litter of mice included in the experimental groups was given either a $45 \%$ fat diet or a $10 \%$ fat diet from weaning and until termination at 11 weeks. In order to make sure the effects observed were due to higher fat at the expense of carbohydrate only, and not decreases in proteins, vitamins or minerals, diets were chosen that added fat as \% Atwater fuel energy (AFE) with isocaloric exchange with carbohydrate. The high fat diet used was 45\% AFE fat diet, code 824053 (45\% kcal from fat, $20 \% \mathrm{kcal}$ from proteins, $35 \%$ from carbohydrate, $4.54 \mathrm{kcal} \mathrm{AFE} / \mathrm{g}$ ), for comparison with the normal fat diet $10 \%$ AFE fat diet, code 824050 (10\% kcal from fat, $20 \%$ kcal from proteins, $70 \%$ from carbohydrate, $3.68 \mathrm{kcal}$ AFE/g), both from SDS Special Diets Services.

2.7. Feed and Water Intake. Since the $45 \%$ fat diet crumbled easily it was not possible to determine the feed intake in a reliable way by weighing the feed in and out of the cages. Instead, feed and water intake were recorded in a selection of mice from each treatment group kept in metabolic cages for $24 \mathrm{~h}$ at age 9-11 weeks, after getting accustomed to the cages the day before. Urine volume was measured and urine and feces were collected for later use not reported in this paper.

2.8. Obesity Determined as Area under the Curve (AUC), Terminal Body Weight and Body Mass Index (BMI). Body weight was recorded weekly from weaning at 3 weeks of age to termination at 11 weeks of age for all $A p c^{M i n /+}$ and $A p c^{+/+}$mice. At termination, nasoanal lengths were recorded for calculation of body mass index (BMI), defined as body weight divided by the nasoanal length squared (in $\mathrm{g} / \mathrm{cm}^{2}$ ). 
Since different indicators of obesity might be more or less suited for evaluation of its relationship with end points such as intestinal tumorigenesis, we evaluated the body weight data in three different ways. The body weight data were analysed as area under the curve (AUC) for body weight recorded from 3 to 11 weeks of age, calculated using the macro in SigmaPlot 12.3 (Systat Software Inc., San Jose, CA, USA), which integrates the area under the curve using the trapezoidal rule. In addition, the body weight data were evaluated as terminal body weight and terminal BMI at 11 weeks (data not shown).

\subsection{Induction and Scoring of Intestinal Tumors. F1 pups} from Min $X o b$ crosses were given a single subcutaneous (s.c.) injection of $25 \mathrm{mg} / \mathrm{kg}$ bw PhIP on day 3-6 after birth, for evaluation of effects of obesity on carcinogen-induced tumors. Separate litters were given a s.c. injection of $0.9 \%$ $\mathrm{NaCl}$ as vehicle controls for scoring of spontaneous tumors only.

The colon and small intestine were removed separately, rinsed in ice-cold phosphate-buffered saline (PBS) and slit open along the longitudinal axis. Intestinal tissues were then spread flat between sheets of filter paper and fixed for at least $48 \mathrm{~h}$ in $10 \%$ neutral buffered formalin prior to staining with 0.2\% methylene blue (Sigma-Aldrich Norway AS). Number, diameter, and localization of tumors in small intestine and colon were scored by transillumination in an inverse light microscope at a magnification of $\times 20$. The scoring was done in order of consecutive mouse numbers unaware of their treatment. Diameters of tumors were scored with an eyepiece graticule. Tumor position along the intestines was registered in $\mathrm{cm}$ from the stomach. For each experimental group, incidence of tumors (number of mice with tumors/number of mice in the group), tumor number (mean number of tumors/mouse $\pm \mathrm{SD}$ ) and tumor diameter in $\mathrm{mm}$ (mean of all tumors in all mice in the group \pm SD) were calculated, for small intestine and colon separately. In addition, size of the tumors was illustrated by curves of distributions of tumor size classes (of $0.25 \mathrm{~mm}$ tumor diameter intervals) calculated as mean number of tumors in each tumor size class for each treatment group. In the C57BL/6J strain, the small intestine is the main target organ for tumorigenesis caused by the Min mutation as well as by PhIP, and very few tumors were found in the colon. Therefore, the colonic tumor data are not shown.

2.10. Glucose Tolerance Test (GTT) and Nonfasted Blood Glucose Measurements. A glucose tolerance test (GTT) was performed on a selection of mice from all treatment groups at age 6 weeks. These mice were fasted for 6 h (8-9 a.m. to 23 p.m.) and were given an intraperitoneal (i.p.) injection of $2 \mathrm{~g} / \mathrm{kg}$ bw D-(+)-glucose (Sigma-Aldrich Norway AS, Oslo, Norway). Glucose in blood obtained by puncture of the saphenous vein was measured with a glucometer (FreeStyle Freedom Lite (Abbott Diabetes Care Inc., Alameda, CA, USA) $5 \mathrm{~min}$ before and 15, 30, 60 and $120 \mathrm{~min}$ after the glucose injection. The area under the glucose tolerance curve (AUC) was calculated from -5 to $120 \mathrm{~min}$, using the macro in SigmaPlot 12.3. When readings were $>27.8 \mathrm{mmol} / \mathrm{L}$, displaying $\mathrm{HIGH}$ in the glucometer, this value was used in the data analysis. This was found for 5, 2 and $48 \%$ of the samples in one or several time points in wt/wt, ob/wt and ob/ob mice, respectively. No samples had glucose readings below $1.1 \mathrm{mmol} / \mathrm{L}$ and showing LOW in the glucometer. Nonfasted blood glucose levels were also measured in all mice at both age 6 and 11 weeks.

2.11. Urine Glucose Measurements. In cases with raised blood glucose concentrations, for instance, in diabetes, glucose may be found in the urine when its concentration in plasma exceeds the renal threshold. In some mice showing high values of blood glucose, urine glucose was also measured by urinalysis dipsticks Siemens Multistix 8 SG purchased from Siemens Healthcare Diagnostics Inc. (Tarrytown, NY, USA).

2.12. Insulin and Insulin-Like Growth Factor (IGF-1) Analyses. Insulin and insulin-like growth factor 1 (IGF-1) were measured in plasma obtained from the mice at sacrifice. ELISA kits from MyBioSource Inc. (San Diego, CA, USA) were used according to the manufacturer's instructions. Optical density (OD) was measured at $450 \mathrm{~nm}$ on a BioTek microplate reader (BioTek Instruments Inc., Winooski, VT, USA). Concentrations were calculated from standard curves on each plate. All samples were diluted 1: 5 in PBS, pH 7.1. The limit of detection was $0.1 \mathrm{ng} / \mathrm{mL}$ for both insulin and IGF-1.

2.13. Cytokine Analyses. The proinflammatory cytokines interleukin-1 $\beta$ (IL-1 $\beta$ ), interleukin-6 (IL-6) and tumor necrosis factor $\alpha$ (TNF $\alpha)$ were measured in plasma obtained from the mice at sacrifice. Bead-based immunoassays $\mathrm{BD}$ Cytometric Bead Array (CBA), from BD Biosciences, San Jose, CA, USA, were used according to the manufacturer's instructions. Data were collected on a BD LSRII flow cytometer (BD Biosciences) and analysed by use of FCAP Array software 3.0 (BD Biosciences). All samples were diluted 1:2 in Assay Diluent included in the CBA kit. The limits of detection were $1.9,1.4$ and $2.8 \mathrm{pg} / \mathrm{mL}$, for IL- $1 \beta$, IL- 6 and $\mathrm{TNF} \alpha$, respectively.

2.14. Long-Term Survival of Untreated ob Mice. The impact of the $o b$ genotype on life-span was examined in groups of untreated $A p c^{M i n /+}$ and $A p c^{+/+}$mice, of all three $o b$ subgroups, $\mathrm{ob} / \mathrm{ob}, \mathrm{ob} / \mathrm{wt}$ and wt/wt, and both genders. The mice were kept under regular observation and euthanized by cervical dislocation when deterioration in general health or quality of life were reached, as judged by clinical observations, body condition and symptoms such as weight loss, dehydration or hunched posture. Survival of each genotype of mice (in days) was depicted as decreasing \% of surviving mice compared with the number of mice present at the start of the experiment.

2.15. Statistical Analyses. The data for each end point (such as body weight, blood glucose levels and tumor numbers) was evaluated on several levels; first on all mice and then further on several strata; age, Apc genotype, $0.9 \% \mathrm{NaCl}$ or $\mathrm{PhIP}$ treatment, gender, $o b$ genotype and $\%$ fat diet. The results 
TABLE 1: Feed and water intake in mice kept in metabolic cages for $24 \mathrm{~h}$.

\begin{tabular}{|c|c|c|c|c|c|c|c|}
\hline$o b$ genotype & $\%$ fat diet & Gender & $n$ & $\begin{array}{c}\text { Feed intake } \\
\text { (g feed/g bw/day) }\end{array}$ & $\begin{array}{c}\text { Feed intake } \\
\text { (kcal AFE/g bw/day) }\end{array}$ & $n$ & $\begin{array}{l}\text { Water intake } \\
\text { (mL/g bw/day) }\end{array}$ \\
\hline \multirow{2}{*}{ wt/wt } & \multirow{2}{*}{10} & $\mathrm{~F}$ & 10 & $0.25 \pm 0.04$ & $0.90 \pm 0.13$ & 10 & $0.25 \pm 0.05$ \\
\hline & & M & 11 & $0.18 \pm 0.05$ & $0.65 \pm 0.19$ & 11 & $0.20 \pm 0.04$ \\
\hline \multirow{2}{*}{$\mathrm{ob} / \mathrm{wt}$} & \multirow{2}{*}{10} & $\mathrm{~F}$ & 10 & $0.22 \pm 0.03$ & $0.82 \pm 0.12$ & 11 & $0.27 \pm 0.06$ \\
\hline & & M & 14 & $0.20 \pm 0.05$ & $0.72 \pm 0.18$ & 15 & $0.22 \pm 0.06$ \\
\hline \multirow{2}{*}{$\mathrm{ob} / \mathrm{ob}$} & \multirow{2}{*}{10} & $\mathrm{~F}$ & 11 & $0.17 \pm 0.04$ & $0.62 \pm 0.14$ & 11 & $0.31 \pm 0.16$ \\
\hline & & M & 8 & $0.16 \pm 0.02$ & $0.59 \pm 0.06$ & 9 & $0.23 \pm 0.10$ \\
\hline \multirow{2}{*}{ wt/wt } & \multirow{2}{*}{45} & $\mathrm{~F}$ & 12 & $0.10 \pm 0.02$ & $0.44 \pm 0.11$ & 12 & $0.18 \pm 0.04$ \\
\hline & & M & 13 & $0.07 \pm 0.03$ & $0.30 \pm 0.14$ & 8 & $0.13 \pm 0.04$ \\
\hline \multirow{2}{*}{$\mathrm{ob} / \mathrm{wt}$} & \multirow{2}{*}{45} & $\mathrm{~F}$ & 12 & $0.09 \pm 0.03$ & $0.41 \pm 0.14$ & 11 & $0.15 \pm 0.05$ \\
\hline & & M & 14 & $0.07 \pm 0.03$ & $0.30 \pm 0.13$ & 10 & $0.12 \pm 0.02$ \\
\hline \multirow{2}{*}{$\mathrm{ob} / \mathrm{ob}$} & \multirow{2}{*}{45} & $\mathrm{~F}$ & 11 & $0.05 \pm 0.02$ & $0.25 \pm 0.07$ & 2 & $0.24 \pm 0.08$ \\
\hline & & M & 8 & $0.07 \pm 0.02$ & $0.31 \pm 0.08$ & 4 & $0.12 \pm 0.01$ \\
\hline
\end{tabular}

Feed and water intake (mean $\pm \mathrm{SD}$ ) were recorded in some of the mice from each treatment group kept in metabolic cages for $24 \mathrm{~h}$ at age 9-11 weeks, after they were getting accustomed to the cages the day before. There were no consistent significant differences in feed and water intake between $A \mathrm{pc}^{\mathrm{Min} /+}$ and $\mathrm{Apc} \mathrm{c}^{+/+}$ mice, or between $0.9 \% \mathrm{NaCl}$ - or PhIP-treated mice, and therefore these data were pooled. $\mathrm{F}=$ females, $\mathrm{M}=$ males, and $n=$ number of mice.

are reported down to the most specific combination of these parameters for which statistically significant differences were found. Because of this complexity, statistical comparisons cannot be shown in a meaningful way on the figures or in Table 1, which give the numerical data. However, the $P$ values of all comparisons are given in the text. All data were presented as mean $\pm S D$, except for the cytokine and insulin data where median and single values were shown, and were analysed using SigmaPlot 12.3. Student's $t$-test or MannWhitney Rank sum test for nonparametric data was used for testing of the survival data. The incidence of colonic tumors was analysed by Fischer exact test (two-tailed probability). Simple and multiple linear regression were used to examine the associations between body weight, glucose, insulin and cytokine levels and number or diameter of small intestinal tumors. For all other data, analysis of variance (ANOVA) was used with an appropriate multiple comparison procedure. When testing the influence of a single factor, one-way ANOVA with the Holm-Sidak test for multiple comparisons was used for parametric data or the Kruskal-Wallis ANOVA on ranks with Dunn's test for multiple comparisons was used for nonparametric data. When testing the influences of two or three factors together the data were analysed by two- or three-way ANOVA, respectively, with the Holm-Sidak test for multiple comparisons. A $P$ value of $<0.05$ was considered statistically significant.

\section{Results}

3.1. Feed and Water Intake. The feed and water intake were recorded in mice kept in metabolic cages for $24 \mathrm{~h}$. When the feed and water intake data were evaluated as $\mathrm{g}$ feed or $\mathrm{mL}$ water/g bw/day, there were no significant differences in feed or water intake between $\mathrm{Apc}^{\mathrm{Min} /+}$ and $\mathrm{Apc}^{+/+}$mice, or between $0.9 \% \mathrm{NaCl}$ - or PhIP-treated mice. Therefore, the data were pooled for $A p c$ genotype and $0.9 \% \mathrm{NaCl}$ or $\mathrm{PhIP}$ treatment, and stratified only for gender, $o b$ genotype and \% fat diet (Table 1).

The feed intake per $\mathrm{g}$ bw was higher in females than in males, based on all mice $(P<0.001)$, and in the subgroups $\mathrm{ob} / \mathrm{wt}(P=0.009)$ and $\mathrm{wt} / \mathrm{wt}(P<0.001)$ mice, but not in $\mathrm{ob} / \mathrm{ob}$ mice. A higher feed intake per $\mathrm{g} b \mathrm{~b}$ in females than in males was also found in a previous experiment [19].

Mice fed a $10 \%$ fat diet had significantly higher feed intake than mice fed a $45 \%$ fat diet $(P<0.001)$. This was also seen in the subgroups ob/ob, ob/wt and wt/wt mice, exposed to either $0.9 \% \mathrm{NaCl}$ or $\mathrm{PhIP}(P<0.001$, for all comparisons).

The ob/ob mice had significantly lower feed intake per $\mathrm{g}$ bw compared with ob/wt and wt/wt mice $(P<0.001$, for both comparisons), whereas ob/wt and wt/wt mice were not significantly different. In females separately, the results were the same as for all mice, whereas in males separately, the differences between the three $o b$ genotypes did not reach significance. The feed intake per mouse was significantly higher in ob/ob mice than in ob/wt and wt/wt mice, but because of the extreme body weight of the ob/ob mice, the intake was lower on a body weight basis.

When the feed intake was compared as intake of $\mathrm{kcal} / \mathrm{g}$ bw during $24 \mathrm{~h}$, the results were essentially the same as for $\mathrm{g}$ feed/g bw (Table 1).

The water intake per $\mathrm{g}$ bw was higher in females than in males, based on all mice $(P<0.001)$, and in the subgroups of mice on a $10 \%$ fat diet and on a $45 \%$ fat diet $(P<0.001$ and $P=0.012$, resp.), and in the subgroup of ob/ob mice $(P=0.003)($ Table 1$)$.

Mice fed a $10 \%$ fat diet had significantly higher water intake per $\mathrm{g}$ bw than mice fed a $45 \%$ fat $\operatorname{diet}(P<0.001)$.

The ob/ob mice had significantly higher water intake per g bw compared with ob/wt and wt/wt mice $(P=0.010$ and $P=0.009$, resp.), whereas ob/wt and wt/wt mice were not significantly different. On the individual level, we observed that many, but not all, of the ob/ob mice had a much higher 


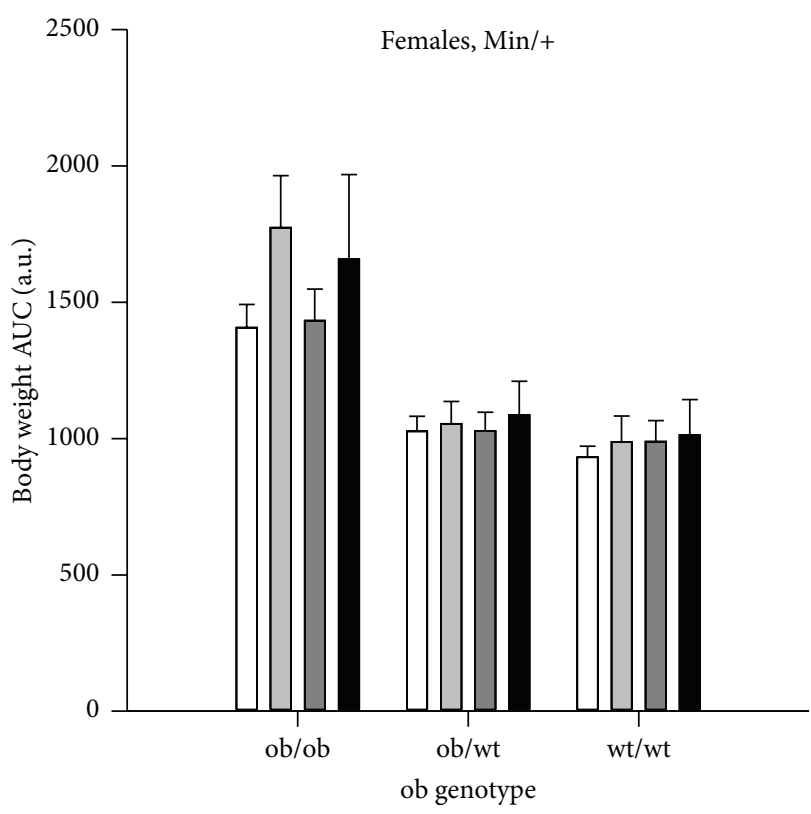

(a)

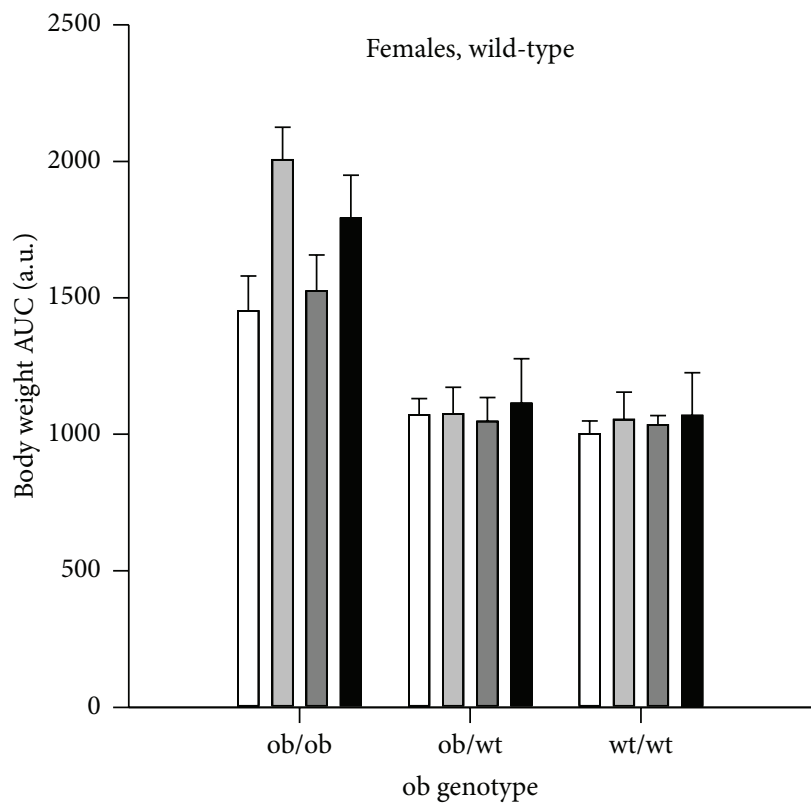

(c)

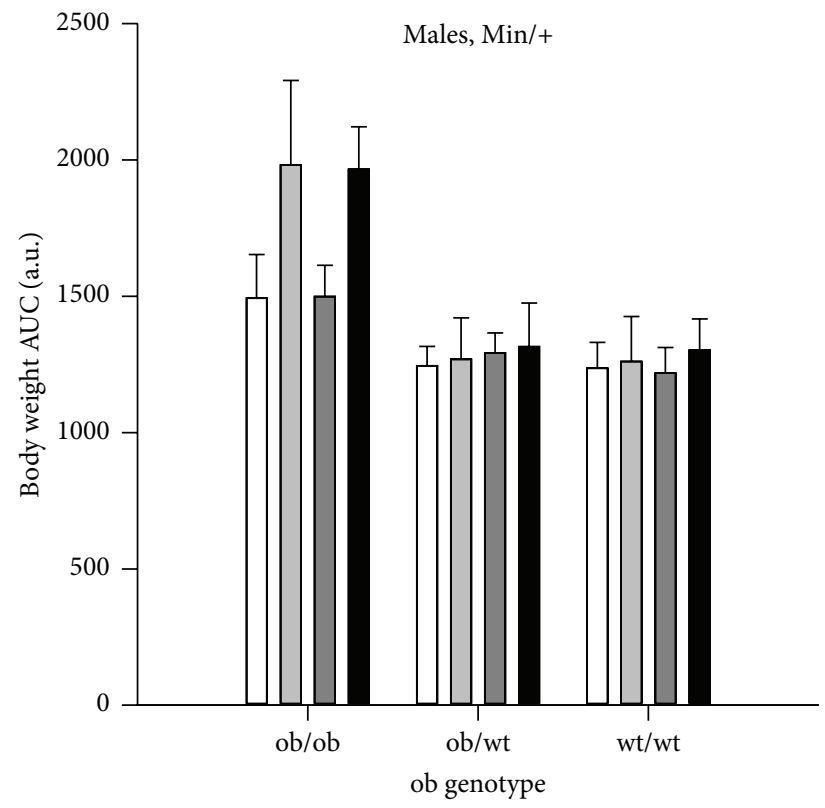

(b)

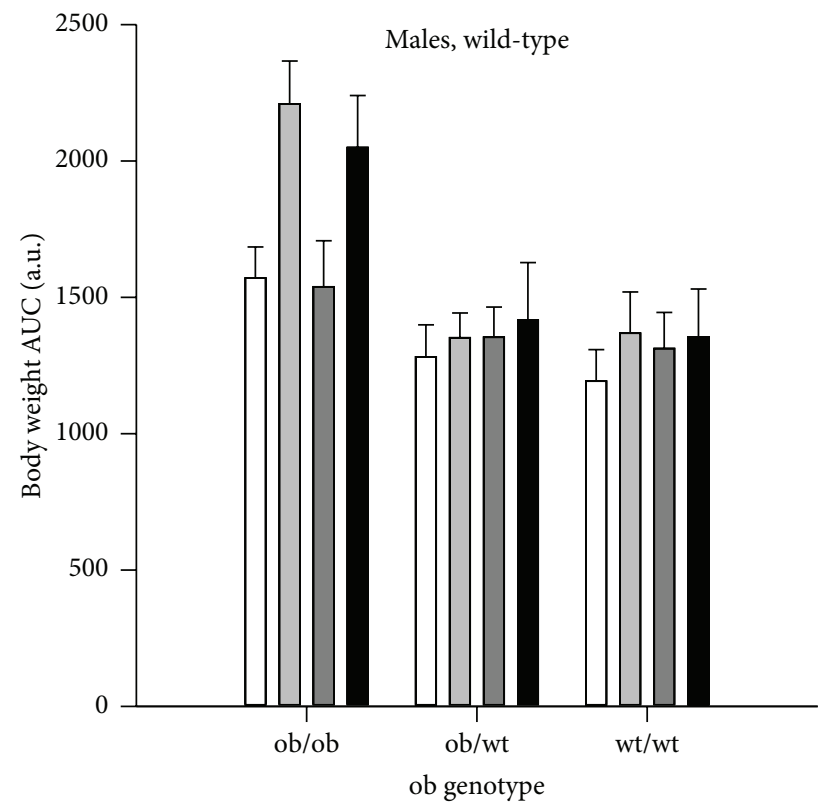

(d)

FIGURE 1: Body weight as area under the curve (AUC). Body weight was recorded weekly from weaning at week 3 until termination at week 11 and is presented for $\mathrm{Apc}^{\mathrm{Min} /+}$ (a) females and (b) males, and $\mathrm{Apc}^{+/+}$(c) females and (d) males (mean \pm SD). The mice were exposed to 0.9\% $\mathrm{NaCl}$ and given a $10 \%$ fat diet (white columns) or $0.9 \% \mathrm{NaCl}$ and a $45 \%$ fat diet (light grey columns), or they were exposed to PhIP and given a $10 \%$ fat diet (dark grey columns) or PhIP and a 45\% fat diet (black columns). $n=10-18$ mice. a.u. $=$ arbitrary units.

water intake as well as higher urine output than ob/wt and wt/wt mice, especially mice with blood glucose above normal levels. This condition appeared to be transient.

3.2. Obesity Determined as Area under the Curve (AUC), Terminal Body Weight and Body Mass Index (BMI). Body weight was compared between the treatment groups $(n=$ 10-18) by calculating the area under the curve (AUC) for the body weight development from weaning at week 3 to termination at week 11 (Figure 1). For this end point, data from both $A p c^{\mathrm{Min} /+}$ and $A p c^{+/+}$were evaluated. The $A p c^{\mathrm{Min} /+}$ mice were lighter than the $A p c^{+/+}$mice $(P<0.001)$. There were no differences between mice treated with $0.9 \% \mathrm{NaCl}$ or $\mathrm{PhIP}$, based on all mice and in the subgroups ob/ob, ob/wt, and $\mathrm{wt} / \mathrm{wt}$ mice. AUC was higher for males than females based on all mice $(P<0.001)$, in the subgroups ob/ob, ob/wt, 


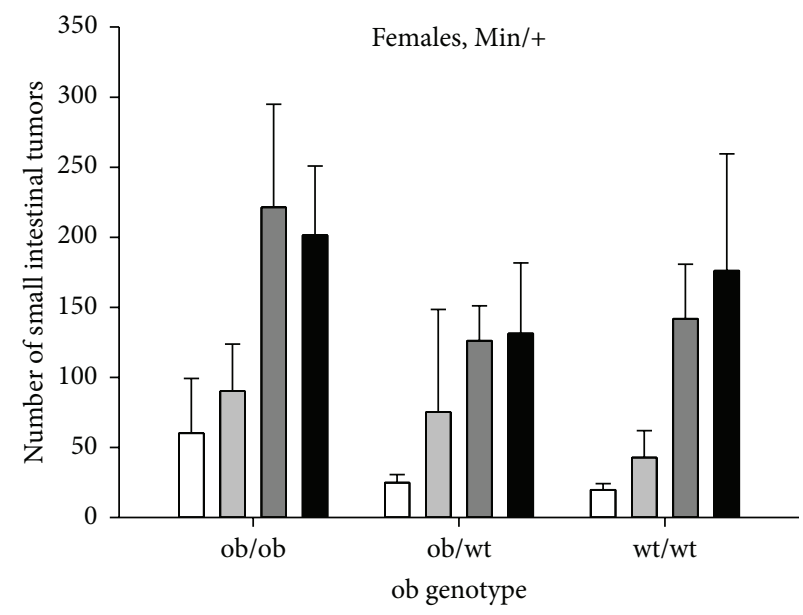

(a)

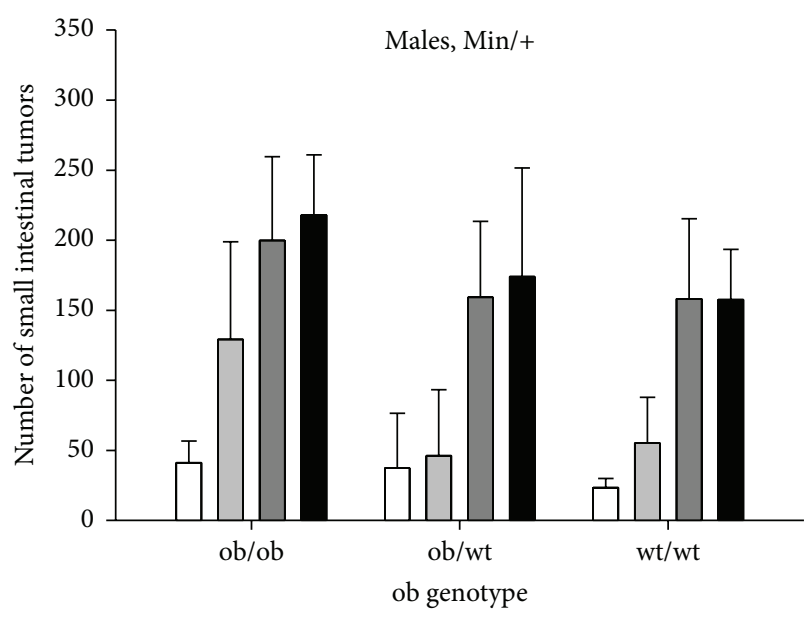

(b)

Figure 2: Number of small intestinal tumors. The number of small intestinal tumors (mean \pm SD) is shown for (a) female and (b) male $A p c^{\mathrm{Min} /+}$ mice with the three $o b$ genotypes, terminated at 11 weeks of age. The mice were exposed to $0.9 \% \mathrm{NaCl}$ and given a $10 \%$ fat diet (white columns) or $0.9 \% \mathrm{NaCl}$ and a $45 \%$ fat diet (light grey columns), or they were exposed to PhIP and given a $10 \%$ fat diet (dark grey columns) or PhIP and a $45 \%$ fat diet (black columns). $n=10-17$ mice.

and $\mathrm{wt} / \mathrm{wt}$ mice $(P<0.001$, for all three comparisons), and in all three $o b$ genotypes on a $45 \%$ fat diet and for ob/wt and $\mathrm{wt} / \mathrm{wt}$ on a $10 \%$ fat diet $(P<0.001$, for all comparisons), but not for ob/ob mice on a $10 \%$ fat diet.

AUC was significantly higher in ob/ob mice compared with ob/wt and wt/wt mice based on all mice $(P<0.001)$ (Figure 1), in female mice $(P<0.001)$ and in male mice $(P<0.001)$ separately $(P$ values similar for both genotype comparisons). The ob/wt mice had higher AUC than the wt/wt mice based on all mice $(P=0.003)$, in females $(P=$ 0.050 ), but not in males, separately, in mice on a $10 \%$ fat diet $(P=0.040)$, but not in mice on a $45 \%$ fat diet, and not in mice treated with either $0.9 \% \mathrm{NaCl}$ or PhIP, separately.

Mice fed a $45 \%$ fat diet were heavier than mice fed a $10 \%$ fat diet based on all mice $(P<0.001)$ (Figure 1$)$, in both female and male ob/ob mice $(P<0.001$, for both comparisons), and in male wt/wt mice $(P=0.005)$.

There were significant interactions between $o b$ genotype and gender $(P=0.011)$, ob genotype and $\%$ fat diet $(P \leq$ $0.001)$ and $o b$ genotype and treatment with $0.9 \% \mathrm{NaCl}$ or $\mathrm{PhIP}(P=0.027)$. There was a significant interaction between gender, \% fat diet and $o b$ genotype $(P=0.019)$, where the gender $\mathrm{X} \%$ fat diet interaction depended on the $o b$ genotype ( $P \leq 0.001$, for all three $o b$ genotypes).

In addition to evaluating body weight as AUC, the terminal body weight and terminal BMI (data not shown) were also calculated for comparison. The body weight results were very much the same whether the data were evaluated as AUC from week 3 to 11 (Figure 1), terminal bw or terminal BMI at 11 weeks (data not shown), except that there was no difference in BMI between ob/wt and wt/wt mice. In addition, BMI was higher in ob/ob females than in males, whereas $\mathrm{ob} / \mathrm{ob}$ males were larger than females for body weight as AUC and terminal body weight.
3.3. Small Intestinal Tumors in Apc $\mathrm{Min} /+^{\mathrm{N}}$ Mice. All Apc $\mathrm{Min/+}$ mice ( $n=10-17$ in each experimental group), regardless of $o b$ genotype, \% fat diet, or $0.9 \% \mathrm{NaCl}$ or PhIP treatment, had small intestinal tumors (adenomas), confirming 100\% incidence of small intestinal tumors as is usually found in the $A p c^{M i n /+}$ mice $[15,16,19]$. No tumors were found in the $A p c^{+/+}$mice. The number of small intestinal tumors was not significantly different between female and male $A p c^{M i n /+}$ mice (Figures 2(a) versus 2(b)). There were no significant interactions between gender and PhIP treatment, $\%$ fat diet or $o b$ genotype for this end point.

The number of small intestinal tumors was significantly higher in ob/ob mice compared with ob/wt mice, based on all mice $(P<0.001)$, in PhIP-treated mice $(P<0.001)$ and in $0.9 \% \mathrm{NaCl}$-treated mice $(P=0.002)$, separately, and in ob/ob mice compared with wt/wt mice, for all mice $(P<0.001)$, in PhIP-treated mice $(P<0.001)$ and in $0.9 \% \mathrm{NaCl}$-treated mice $(P<0.001)$, separately (Figure 2$)$. The number of small intestinal tumors was not significantly different in ob/wt mice compared with in wt/wt mice, based on all mice or in PhIPtreated or $0.9 \% \mathrm{NaCl}$-treated mice separately. There was a borderline significant interaction between $o b$ genotype and PhIP treatment $(P=0.049)$.

The $45 \%$ fat diet increased the number of small intestinal tumors compared with the $10 \%$ fat diet, in all mice $(P<$ $0.001)$, in vehicle-treated mice $(P<0.001)$, but not in PhIPtreated mice. There was a significant interaction between $\%$ fat diet and PhIP treatment $(P=0.007)$.

$\mathrm{PhIP}$ increased the number of small intestinal tumors compared with the vehicle $0.9 \% \mathrm{NaCl}$, in all mice $(P<0.001)$, in mice given a $10 \%$ fat $\operatorname{diet}(P<0.001)$ and a $45 \%$ fat $\operatorname{diet}(P<$ 0.001). PhIP increased the number of small intestinal tumors in ob/ob mice $(P<0.001)$, in ob/wt mice $(P<0.001)$ and in wt/wt mice $(P<0.001)$, and in both females $(P<0.001$, 
for all three comparisons) and males $(P<0.001$, for all three comparisons) of each $o b$ genotype (Figure 2).

The small intestinal tumors had diameters of $0.15-$ $4.30 \mathrm{~mm}$. The statistical evaluation of differences in small intestinal tumor size between the experimental groups is described in the following (data not shown). In addition, this is illustrated with size distribution curves (Figure 3). Based on all mice, the small intestinal tumors were significantly larger in male mice compared with in female mice $(P<0.001)$. This was observed within all the PhIP-exposed mice $(P<0.001)$, also among the subgroups of PhIP-treated ob/ob mice $(P<$ $0.001)$, ob/wt mice $(P=0.006)$ and wt/wt mice $(P<0.001)$, but not in $0.9 \% \mathrm{NaCl}$-treated mice. The males had larger tumors than the females also in the subgroup of ob/ob mice on a $10 \%$ fat $\operatorname{diet}(P<0.001)$ and on a $45 \%$ fat $\operatorname{diet}(P<0.001)$, in ob/wt mice on a $45 \%$ fat diet $(P<0.001)$, and in wt/wt mice on a $10 \%$ fat diet $(P<0.001)$.

The diameter of the small intestinal tumors was significantly higher in all ob/ob mice compared with ob/wt and wt/wt mice ( $P<0.001$, for both comparisons), but not in ob/wt compared with wt/wt mice (Figure 3, data not shown).

The effect of diet on the size of the small intestinal tumors was evaluated for both genders and is illustrated with size distribution curves for the females in Figures 3(a) and 3(b). The diameter of the small intestinal tumors was not significantly different between mice on a $10 \%$ fat diet versus on a $45 \%$ fat diet, based on all mice. Some statistically significant differences were observed in various subgroups, but these differences were not consistent in direction with regard to \% fat diet and may therefore be due to chance. The tumors were not significantly larger after a $45 \%$ fat diet in the $0.9 \% \mathrm{NaCl}$-exposed or in the PhIP-exposed subgroups of mice. But this was the case in PhIP-exposed ob/wt and wt/wt mice $(P<0.001$, for both comparisons), but not for the PhIPexposed ob/ob mice. Both female and male ob/ob mice had significantly smaller tumors after a $45 \%$ fat diet compared with a $10 \%$ fat diet $(P<0.001$, for both comparisons), possibly indicating formation of new tumors.

The effect of PhIP exposure on the size of the small intestinal tumors was evaluated for both genders and is illustrated with size distribution curves for the males in Figures 3(c) and 3(d). Based on all mice, the small intestinal tumors were significantly larger after PhIP exposure compared with $0.9 \%$ $\mathrm{NaCl}$ exposure $(P<0.001)$. This was also observed in females and males separately, and in mice on a $10 \%$ fat diet and a $45 \%$ fat diet separately ( $P<0.001$, for all comparisons). The small intestinal tumors were significantly larger after PhIP exposure compared with $0.9 \% \mathrm{NaCl}$ exposure in all ob/ob mice $(P<$ $0.001)$, in ob/wt mice on a $10 \%$ fat diet $(P<0.001)$ and a $45 \%$ fat diet $(P<0.001)$, and in wt/wt mice on $45 \%$ fat diet $(P<0.001)$. Within each gender separately, this was also the case for the subgroups of all three ob genotypes $(P<0.001$, for all comparisons).

There were significant statistical interactions between \% fat diet, gender and $o b$ genotype $(P \leq 0.001)$, PhIP treatment, gender and $o b$ genotype $(P=0.008)$, PhIP treatment, $\%$ fat diet and $o b$ genotype $(P \leq 0.001)$, between PhIP treatment and gender $(P=0.009)$, and between PhIP treatment and \% fat diet $(P=0.036)$, for this end point.
3.4. Colonic Tumors in Apc $\mathrm{Min} /+^{\mathrm{M}}$ Mice. In the C57BL/6J strain, the small intestine is the main target organ for tumorigenesis caused by the Min mutation as well as by PhIP. Very few tumors were found in the colon in this experiment (Figure 4), adding no additional insight. Therefore, the data for incidence, number and size of the colonic tumors are not shown.

3.5. Localization of Tumors in the Small Intestine and Colon. In mice given the $10 \%$ fat diet, the majority of small intestinal tumors were localized in the distal two-thirds, that is, in middle and distal parts, of the small intestine (Figure 4), as is usually observed in the $A p c^{\mathrm{Min} /+}$ mouse $[15,16,19]$. In the ob/ob mice, there were unusually high numbers of small intestinal tumors also in the proximal part, whereas in ob/wt and wt/wt mice there were much fewer tumors in this area. This distribution of tumors was observed both in $0.9 \% \mathrm{NaCl}$ treated (Figure 4(a)) and PhIP-treated (Figure 4(b)) mice, and after both treatments the tumor numbers were higher in this area with a $45 \%$ fat diet compared with a $10 \%$ fat diet. The few colonic tumors present were localized mainly in the middle to distal part of the colon.

3.6. Glucose Tolerance Test (GTT) and Nonfasted Blood Glucose. Based on the AUC values from the GTT test performed at 6 weeks of age, AUC in $A p c^{M i n /+}$ mice were higher than in $A p c^{+/+}$mice, and AUC in PhIP-treated mice was higher than in $0.9 \% \mathrm{NaCl}$-treated mice; however, these comparisons did not reach statistical significance. The data for $A p c^{\mathrm{Min} /+}$ and $A \mathrm{pc}^{+/+}$mice were therefore pooled in the curves of blood glucose levels after challenge (Figure 5). There were 5-9 mice in each experimental group, except 4 in one group; female wt/wt mice exposed to PhIP and a $45 \%$ fat diet. In GTT, there was no significant difference (n.s.) between the genders, but the general tendency based on all mice was higher levels in males than in females, differing between the subgroups with females higher than males in ob/ob mice (n.s.), and males higher than females in ob/wt $(P=0.002)$ and wt/wt mice (n.s.).

The ob/ob mice showed a much slower decrease in blood glucose than both the ob/wt and wt/wt mice $(P<0.001$, for both comparisons) (Figure 5). This was also observed in females and males separately, and in mice on $45 \%$ fat diet ( $P<0.001$, for all comparisons). The ob/wt and wt/wt mice were not significantly different. In mice on a $10 \%$ fat diet, only the difference between ob/ob and wt/wt mice reached significance $(P<0.001)$. The male ob/wt mice had actually higher AUC than ob/ob mice both after treatment with $0.9 \%$ $\mathrm{NaCl}$ and PhIP on the 10\% fat diet (Figures 5(b) and 5(d)).

Mice on a $45 \%$ fat diet had a slower blood glucose decrease after challenge than mice on a $10 \%$ fat diet $(P<$ 0.001) (Figure 5). This was also observed in the subgroups $\mathrm{ob} / \mathrm{ob}$ mice, ob/wt mice and wt/wt mice $(P<0.001$, for all comparisons). Strikingly, the ob/ob mice on a $45 \%$ fat diet in particular had much higher and prolonged blood glucose levels after challenge, indicating severe blood glucose dysregulation in both genders (Figure 5).

There was a significant interaction between gender and $o b$ genotype $(P=0.002)$ and between $\%$ fat diet and $o b$ genotype $(P<0.001)$ in the GTT data. 


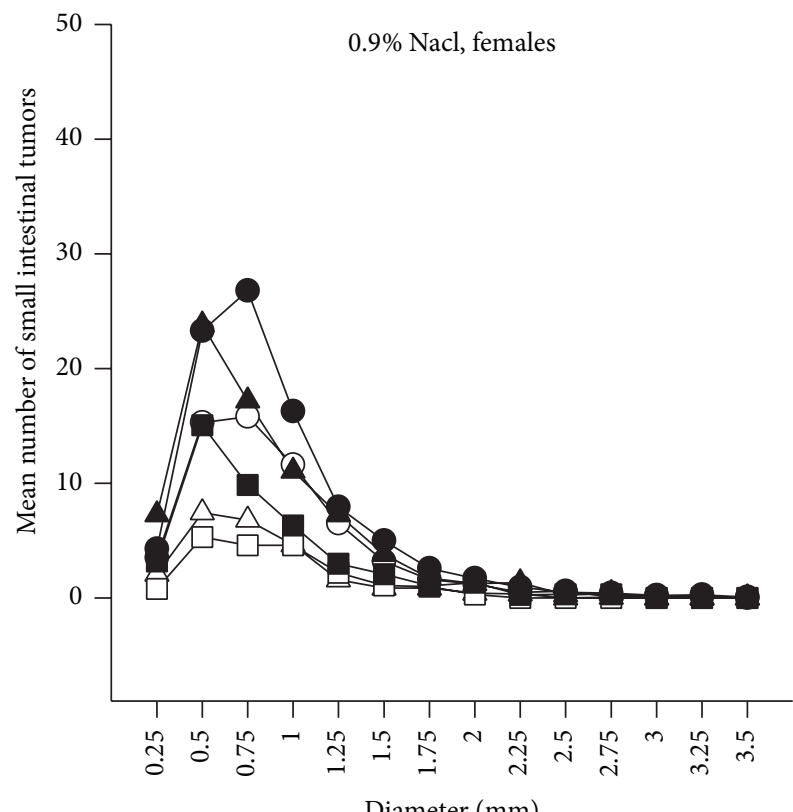

Diameter ( $\mathrm{mm})$

$10 \%$ fat diet $45 \%$ fat diet

(a)

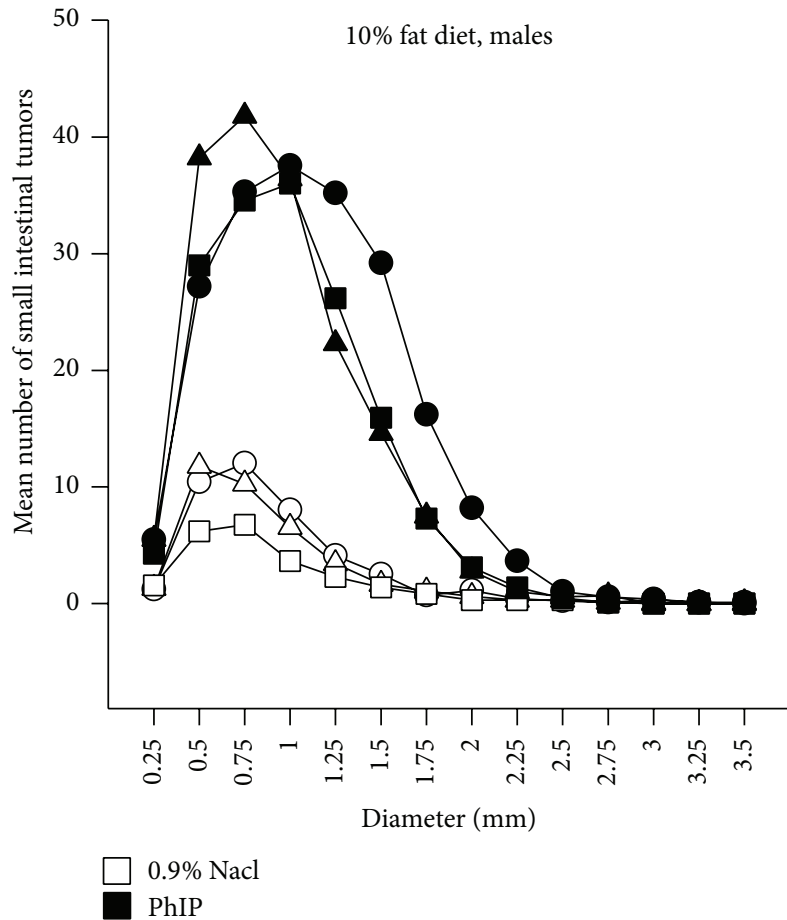

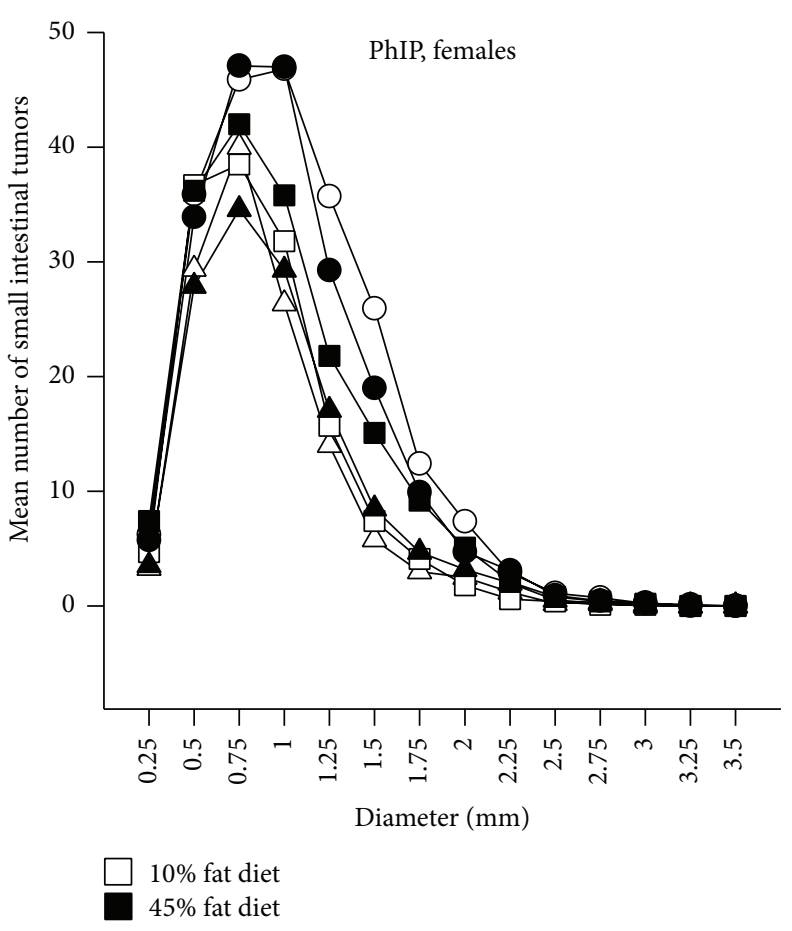

(b)

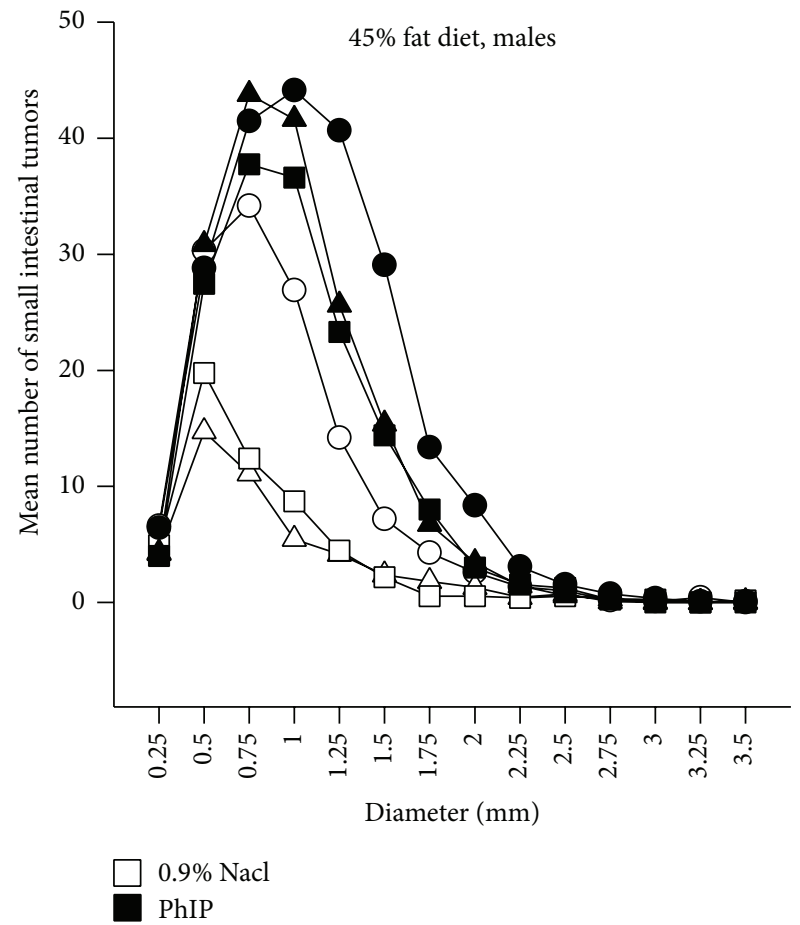

(d)

FIGURE 3: The size of the small intestinal tumors. This is illustrated by curves of distributions of tumors size classes (of $0.25 \mathrm{~mm}$ tumor diameter intervals) calculated as mean number of tumors in each tumor size class for each treatment group. The effect of a $45 \%$ fat diet compared with a $10 \%$ fat diet is shown for female $A p c^{M i n /+} X L e p^{o b / o b}$ mice $(\bigcirc), A p c^{M i n /+} X L e p^{o b / w t}(\triangle)$ and $A p c^{M i n /+}$ X Lep ${ }^{w t / w t}$ mice (口) on a $10 \%$ fat diet, and the same genotypes on a $45 \%$ fat diet (filled symbols) exposed to (a) $0.9 \% \mathrm{NaCl}$, or (b) PhIP. The effect of exposure to PhIP compared with

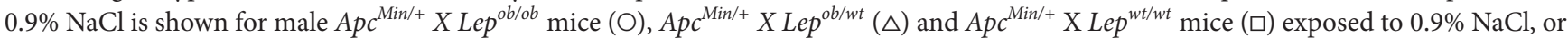
the same genotypes exposed to PhIP (filled symbols) on (c) a 10\% fat diet, or (d) a 45\% fat diet. $n=10-17$ mice. 


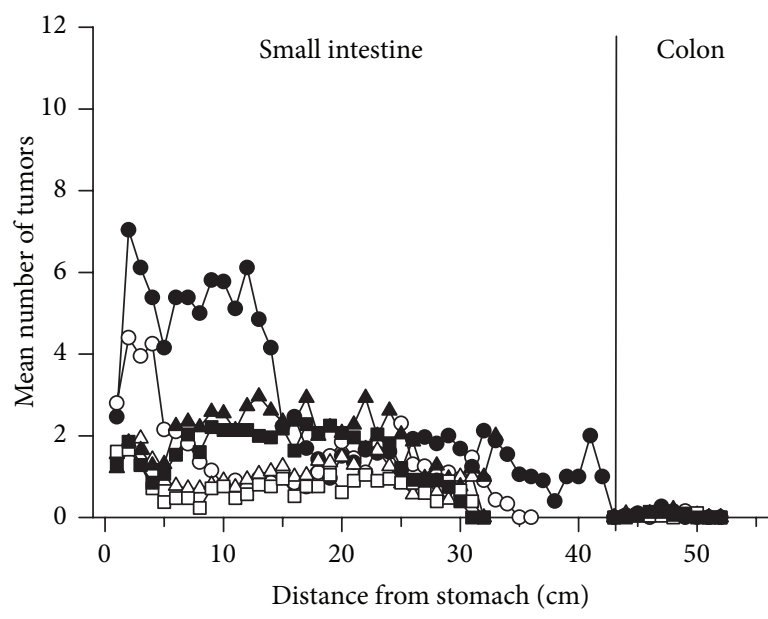

(a)

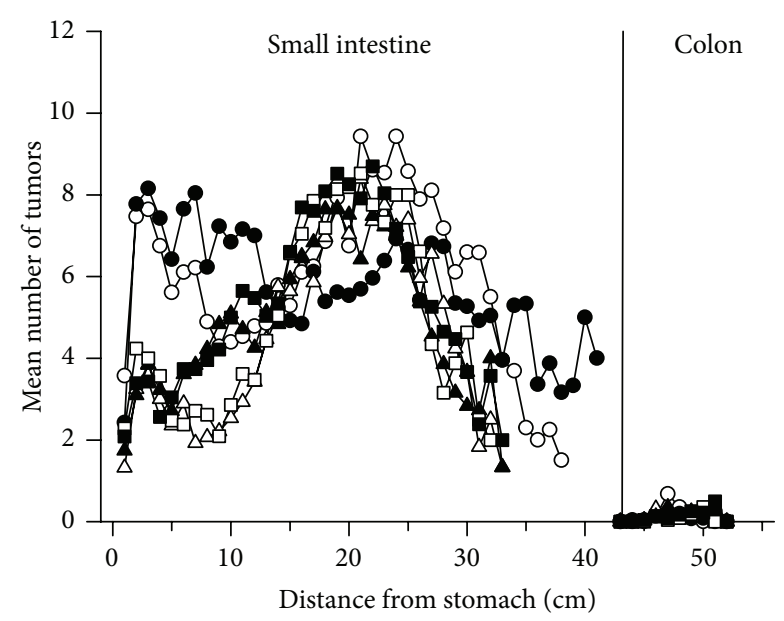

(b)

FIGURE 4: Localization of tumors along the small intestine and colon. This is shown for pooled female and male Apc $c^{\mathrm{Min} /+} X \mathrm{Lep} \mathrm{ob}^{\mathrm{ob}}$ mice (O), $A p c^{M i n /+} X L e p^{o b / w t}(\triangle)$ and $A p c^{M i n /+}$ X Lep ${ }^{w t / w t}$ mice ( $\square$ ) on a $10 \%$ fat diet (open symbols) or a $45 \%$ fat diet (filled symbols) treated with (a) $0.9 \% \mathrm{NaCl}$ or (b) PhIP. The tumor position is given as distance from the stomach measured in $\mathrm{cm}$. Mean number of tumors/cm intestine for the mice in each experimental group was scored. $n=10-17$ mice.

According to WHO [20], diagnostic criteria for humans with impaired glucose tolerance (IGT) are 7.8-11.1 mmol/L $2 \mathrm{~h}$ after an oral GTT of $75 \mathrm{~g}$ glucose, and levels above $11.1 \mathrm{mmol} / \mathrm{L}$ confirm diabetes. Regarding these levels also relevant for mice, we found IGT at the $2 \mathrm{~h}$ time point in the GTT in 17\% and $40 \%, 50 \%$ and $80 \%, 60 \%$ and $58 \%, 56 \%$ and $83 \%, 93 \%$ and $92 \%$, and $100 \%$ and $82 \%$, of the female and male mice, in the treatment groups $\mathrm{wt} / \mathrm{wt}$, ob/wt and ob/ob given a $10 \%$ fat diet, and $\mathrm{wt} / \mathrm{wt}$, ob/wt and ob/ob given a $45 \%$ fat diet, respectively. A diabetic level of glucose at the $2 \mathrm{~h}$ time point in the GTT was found in $0 \%$ and $0 \%, 20 \%$ and $20 \%, 20 \%$ and $50 \%, 0 \%$ and $33 \%, 21 \%$ and $67 \%$, and $100 \%$ and $82 \%$, of the female and male mice in the same treatment groups as above, respectively.

Nonfasted blood glucose levels were also measured in all mice at both age $6(n=10-18)$ and $11(n=9-17)$ weeks (data not shown). Based on all mice, there were higher blood glucose levels measured at week 6 compared with at week 11 $(P<0.001)$, but this difference varied between the subgroups. The $A p c^{M i n /+}$ mice had significantly higher blood glucose levels than $A p c^{+/+}$mice at 11 weeks $(P<0.001)$, but not at 6 weeks, confirming the GTT results. Based on all data, this was most pronounced in PhIP-exposed mice $(P<0.001)$, and in the ob/ob mice $(P<0.001)$. However, at 11 weeks separately, this difference between $A p c$ genotypes was also found in the $\mathrm{wt} / \mathrm{wt}$ mice $(P=0.038)$, but not in the ob/wt mice.

PhIP-treated mice had significantly higher blood glucose levels than $0.9 \% \mathrm{NaCl}$-treated mice $(P<0.001)$ at week 11 , but not at week 6 , confirming the GTT results. This was also observed in the subgroup $A p c^{\mathrm{Min} /+}$ mice $(P<0.001)$, in mice given a $10 \%$ fat $\operatorname{diet}(P<0.001)$ and in the ob/ob mice $(P<$ $0.001)$, but not in the subgroup $A p c^{+/+}$mice, in mice on a $45 \%$ fat diet or in ob/wt and wt/wt mice.

The nonfasted blood glucose data for comparisons between genders, $o b$ genotypes and diets both at 6 and 11 weeks (data not shown) were essentially similar to the data from the GTT test.

3.7. Urine Glucose. In some mice showing high values of blood glucose, urine glucose was also measured by urinalysis dipsticks. These were mostly ob/ob mice, and 15 of the 23 $(65 \%) \mathrm{ob} / \mathrm{ob}$ mice examined had glucose in their urine, whereas 8 of 23 (35\%) had not. Among the ob/ob mice with glucose in the urine, all were females and mostly of $A p c^{\mathrm{Min} /+}$ genotype and on $45 \%$ fat diet and had received either $0.9 \%$ $\mathrm{NaCl}$ or PhIP. However, also two examined female $A p c^{+/+}$ mice with wt/wt $o b$ genotype on $45 \%$ fat diet exposed to $0.9 \%$ $\mathrm{NaCl}$ had glucose in their urine.

3.8. Insulin and IGF-1. Insulin and IGF-1 levels were measured in plasma obtained from the mice at termination. Six samples were analyzed from each experimental group with ANOVA, three from each gender. The levels of IGF-1 were below the limit of detection, $0.1 \mathrm{ng} / \mathrm{mL}$, whereas insulin was detected in all samples (Figures 6(a) and 6(b)). The ob/ob mice had significantly higher levels of insulin than mice with $\mathrm{ob} / \mathrm{wt}$ or wt/wt genotypes based on all mice $(P<0.001$, for both comparisons), and also in the subgroups of both Apc genotypes, both genders, both diet groups and in $0.9 \% \mathrm{NaCl}-$ treated mice ( $P$ values were $<0.001-0.036$ ). The ob/wt and $\mathrm{wt} / \mathrm{wt}$ mice were not significantly different. In PhIP-treated mice, only the comparison between ob/ob and wt/wt reached significance $(P=0.012)$. The $A p c^{+/+}$mice had higher insulin levels than $A p c^{\mathrm{Min} / \mathrm{+}}$ mice based on all mice $(P=0.028)$ and in the subgroup of males separately $(P=0.031)$. PhIP-treated mice had higher insulin levels than $0.9 \% \mathrm{NaCl}$-treated mice based on all mice $(P=0.026)$. Males (Figure $6(\mathrm{~b}))$ had higher insulin levels than females (Figure 6(a)) based on all mice $(P=0.015)$, and in the subgroups of $A p c^{+/+}$mice $(P=0.026)$ 


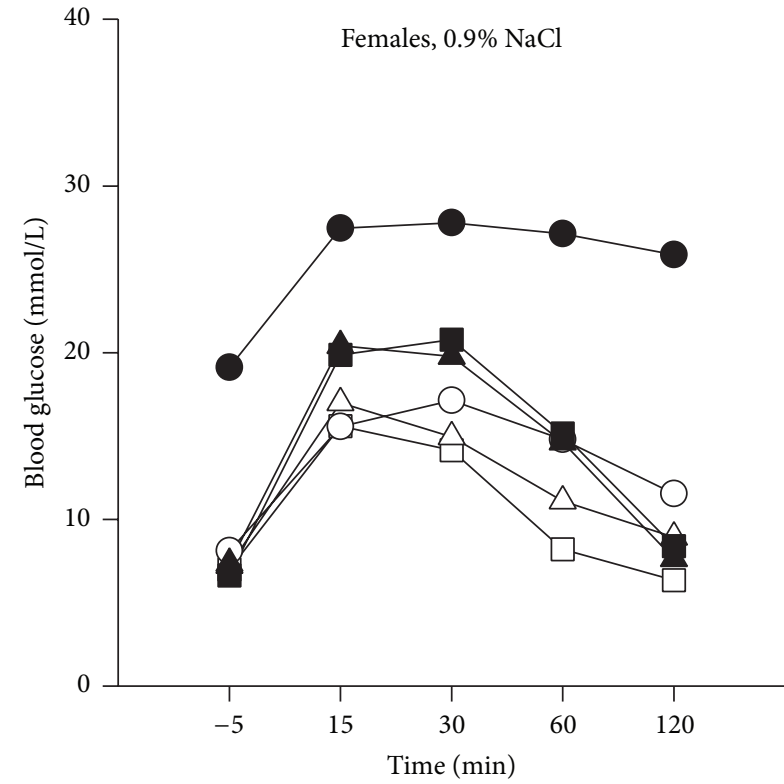

(a)

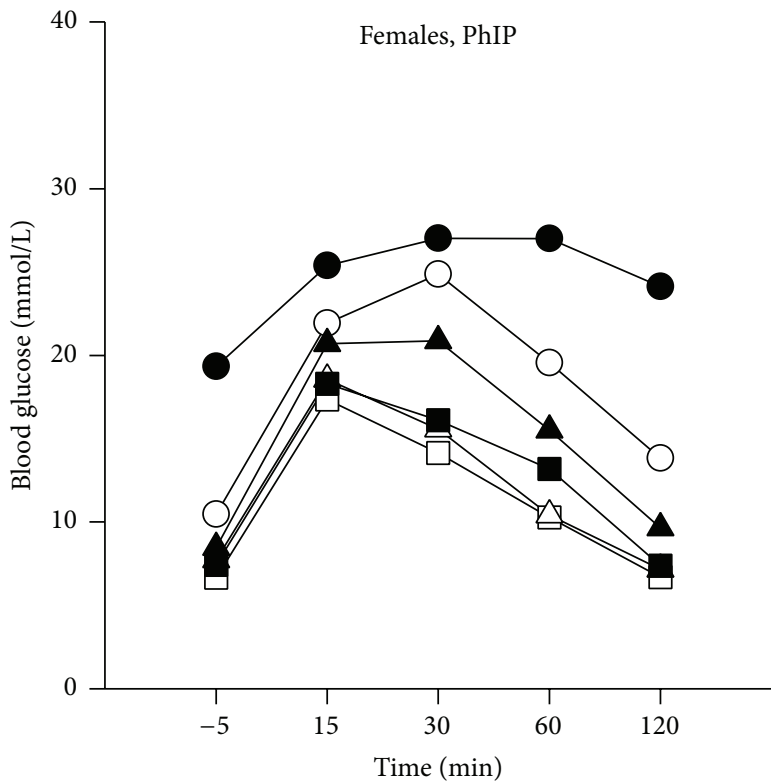

(c)

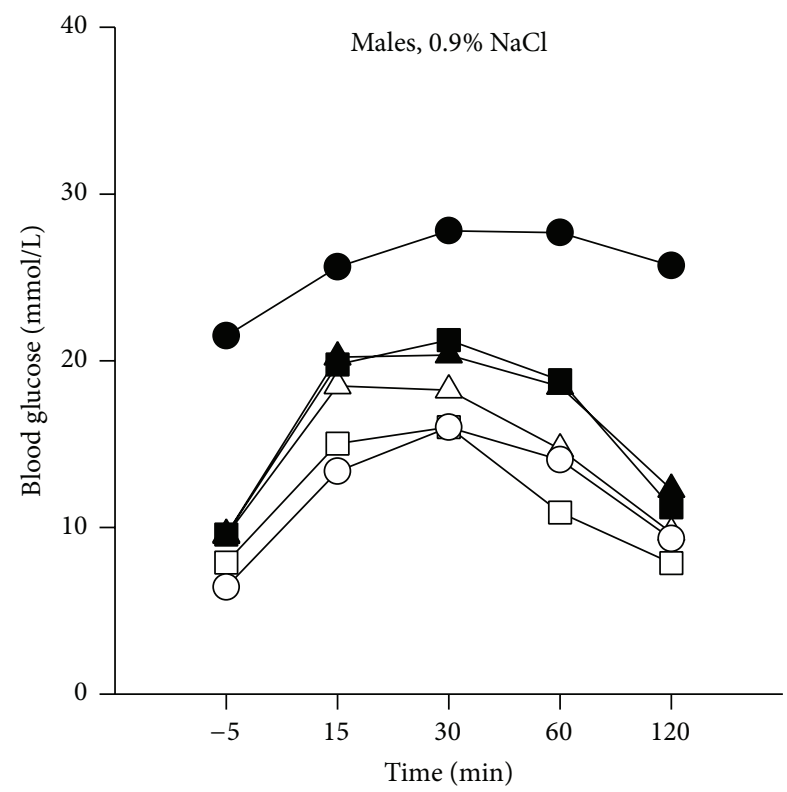

(b)

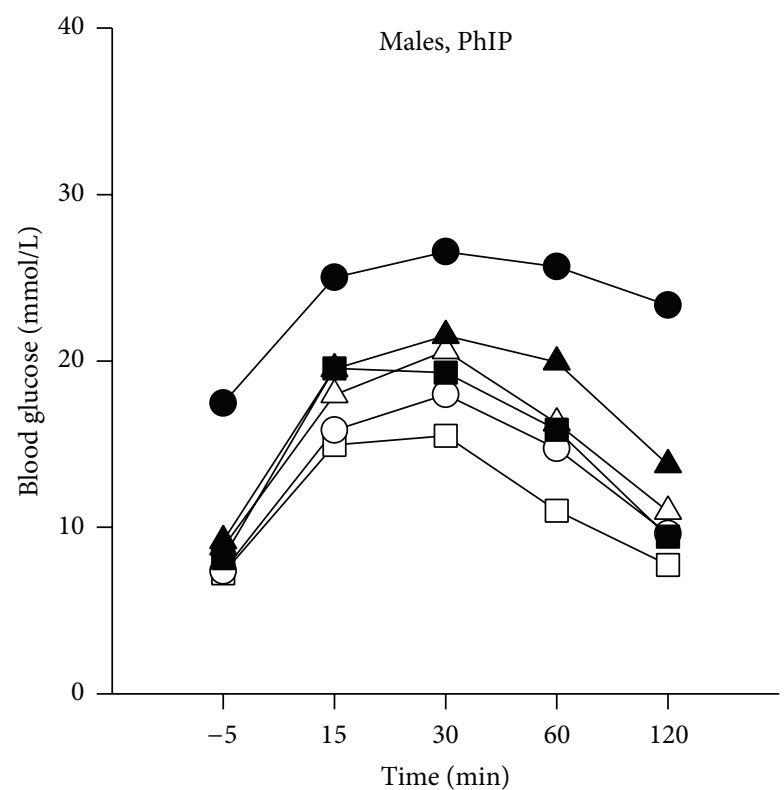

(d)

FigURE 5: Blood glucose levels as area under the curve (AUC) from a glucose tolerance test (GTT). The GTT was performed on mice fasted for $6 \mathrm{~h}$ at 6 weeks of age. Blood glucose was measured $5 \mathrm{~min}$ before and 15, 30, 60 and $120 \mathrm{~min}$ after an i.p. injection of $2 \mathrm{~g} / \mathrm{kg}$ bw glucose. The data were pooled for $\mathrm{Apc}^{\mathrm{Min} /+}$ and $\mathrm{Apc}^{+/+}$mice. The mice were treated with either $0.9 \% \mathrm{NaCl}$, (a) females and (b) males, or with PhIP, (c) females and (d) males. The mice had ob genotype ob/ob $(O)$, ob/wt $(\triangle)$ or wt/wt $(\square)$ and were given a $10 \%$ fat diet (open symbols) or a $45 \%$ fat diet (filled symbols). $n=4-9$ mice.

and $o b \mathrm{wt} / \mathrm{wt}$ mice $(P=0.009)$. There were no significant differences in insulin levels between mice on a $10 \%$ or a $45 \%$ fat diet.

3.9. Cytokines. The proinflammatory cytokines IL-1 $\beta$, IL6 and $\mathrm{TNF} \alpha$ were measured in plasma obtained from the mice at termination. Six samples were analyzed from each experimental group with ANOVA, three from each gender. The levels of IL-1 $\beta$ were below the limit of detection, $1.9 \mathrm{pg} / \mathrm{mL}$, in all samples, whereas $78 \%$ and $46 \%$ of the samples had detectable levels of IL- 6 and TNF $\alpha$, respectively. No statistically significant differences were found in levels of IL-6 between any treatment groups (Figure 6(c)). Regarding $\mathrm{TNF} \alpha$, the ob/ob mice had significantly higher levels than mice with ob/wt or wt/wt genotypes based on all mice 


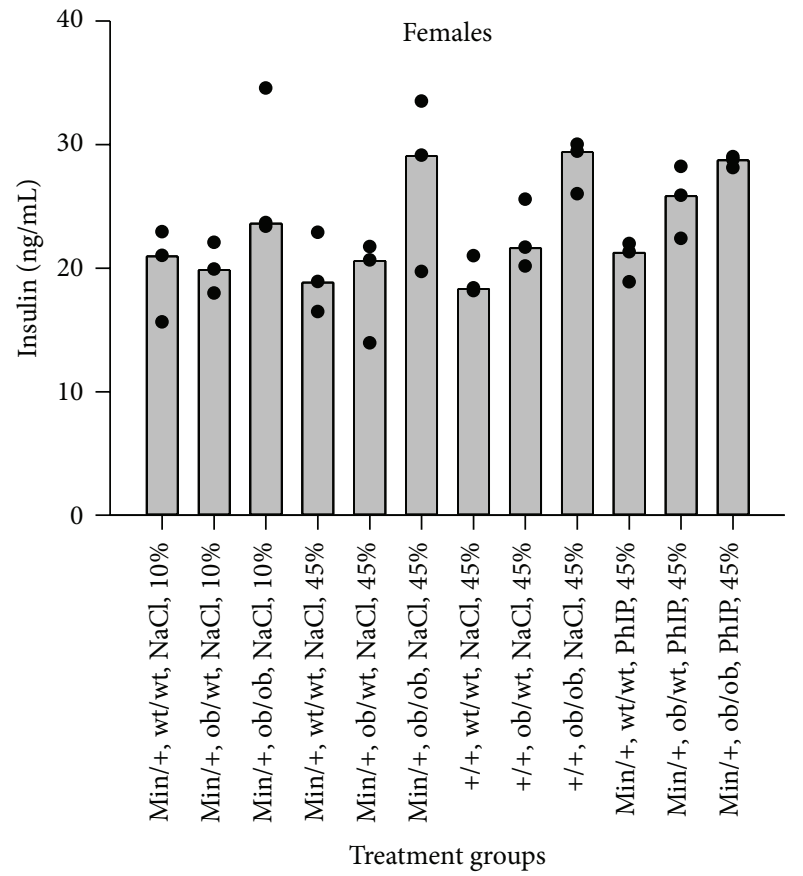

(a)

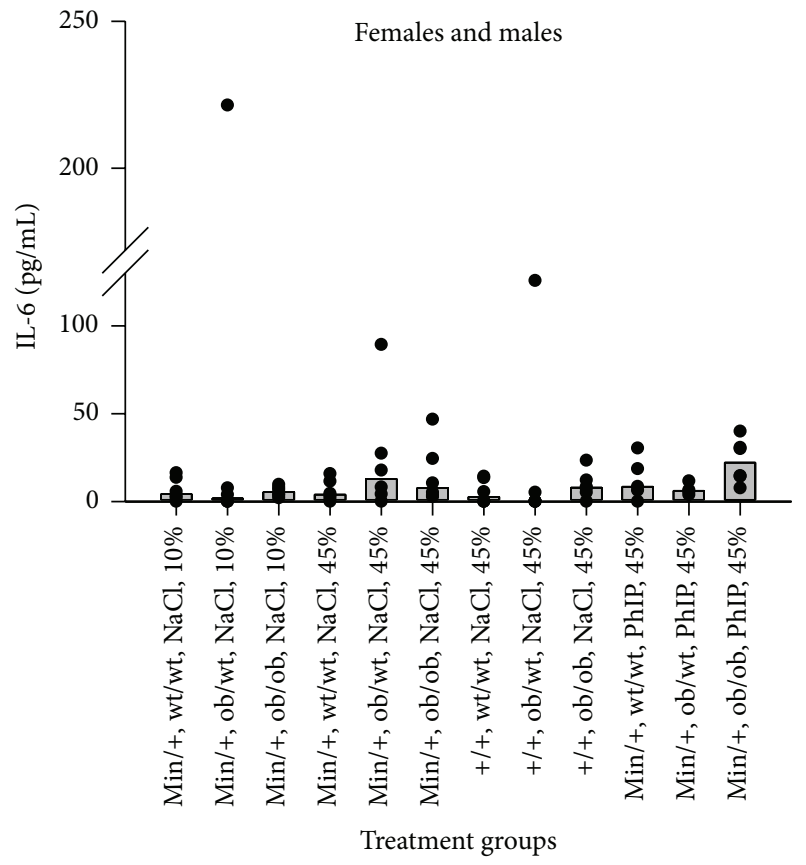

(c)

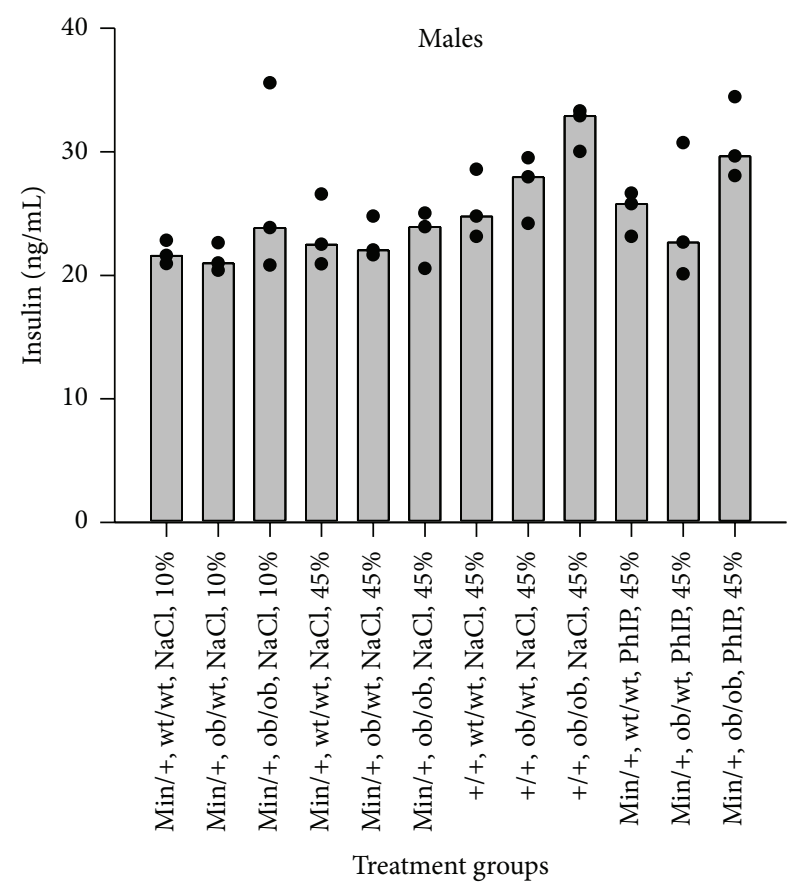

(b)

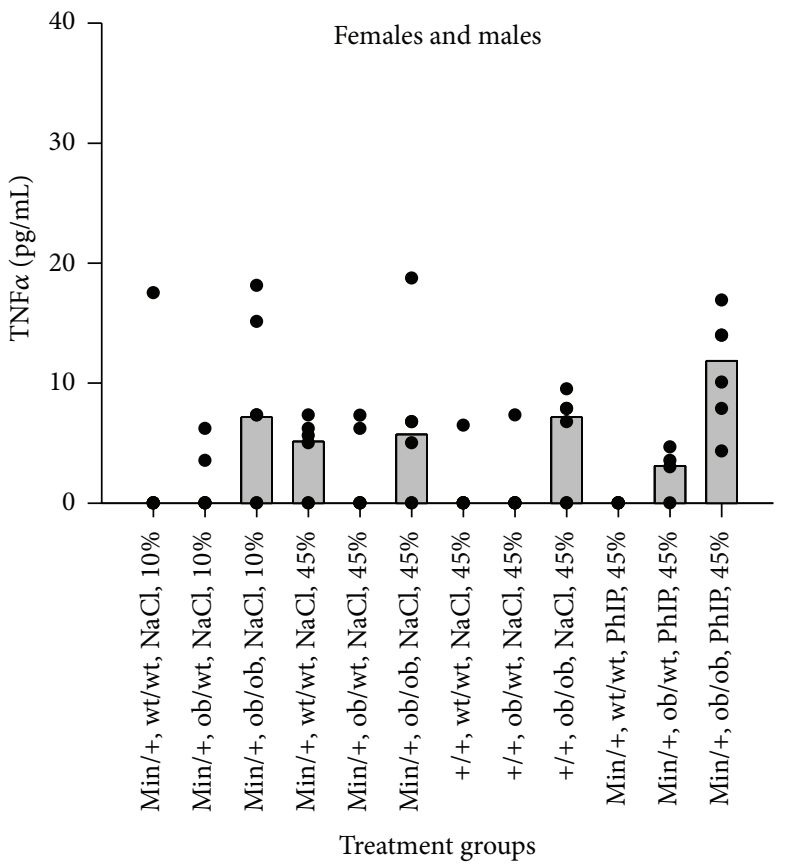

(d)

FIGURE 6: Levels of insulin and the proinflammatory cytokines IL-6 and TNF $\alpha$ in plasma. Insulin levels (ng/mL) were measured with ELISA in plasma obtained from the mice at termination, for (a) females and (b) males (median and individual values are shown as columns and dots, resp.). IL-6 (c) and TNF $\alpha$ (d) levels (both in pg/mL) were measured with bead-based immunoassays and analysed by flow cytometer in plasma obtained from the mice at termination. The data shown are from females and males combined (median and individual values are shown as columns and dots, resp.). $n=6$ mice ( 3 of each gender).

$(P<0.001$, both comparisons), whereas ob/wt and $\mathrm{wt} / \mathrm{wt}$ were not significantly different (Figure 6(d)). The significant difference in TNF $\alpha$ levels between mice with ob/ob genotype and $\mathrm{ob} / \mathrm{wt}$ or wt/wt genotypes was seen in the mice given a $45 \%$ fat diet ( $P=0.002$, both comparisons), but not in the mice given a $10 \%$ fat diet. We found no significant differences in TNF $\alpha$ levels between mice exposed to $0.9 \% \mathrm{NaCl}$ or $\mathrm{PhIP}$ (Figure 6(d)). 
3.10. Correlations between Body Weight and Glucose, Insulin and Cytokine Levels. The strength of the association between the three different end points used for body weight and the other end points examined in this experiment was evaluated by simple linear regression (Table 2). The coefficient of determination $\left(R^{2}\right)$ expresses the \% of variation in the dependent variable than can be explained by the independent variables. The percentage of the variation in the nonfasted blood glucose levels measured at 6 weeks that could be explained by the body weight data was $46-57 \%$, in the blood glucose levels measured at 11 weeks it was $33-43 \%$, and in the insulin levels it was $32-48 \%$, depending on which parameter was used for body weight ( $P<0.001$, for all comparisons). The percentage of the variation in the TNF $\alpha$ levels that could be explained by AUC and terminal body weight was around $20 \%$ ( $P=0.021$ and $P=0.013$, resp.), whereas for BMI this association was not statistically significant.

3.11. Correlations between Body Weight, Glucose, Insulin and Cytokine Levels and Intestinal Tumorigenesis. The strength of the association between the body weight and the other end points examined in this experiment and number and diameter of small intestinal tumors was evaluated by simple linear regression (Table 3). Body weight evaluated as AUC from week 3 to 11 and nonfasted blood glucose levels at week 6 and week 11 could explain $11 \%, 12 \%$, and $18 \%$ of the variation in the number of small intestinal tumors, respectively $(P<$ 0.001 , for all three variables). When evaluating number of small intestinal tumors with all three body weight parameters and blood glucose at both 6 and 11 weeks together with multiple linear regression, the association was statistically significant for body weight as AUC, terminal bw and blood glucose at 11 weeks $(P<0.001$, for all three variables), explaining $31 \%$ of the variation in tumor number.

The association found by simple linear regression with diameter of small intestinal tumors and $\mathrm{TNF} \alpha$, body weight evaluated as AUC from week 3 to 11 and nonfasted blood glucose levels at week 6 and week 11, was 31\%, 14\%, 9\% and $8 \%$, respectively $(P<0.001$, except for TNF $\alpha$ with $P=0.003$ ) (Table 3 ). When evaluating diameter of small intestinal tumors with all three body weight parameters and blood glucose at both 6 and 11 weeks together with multiple linear regression, the association was statistically significant for body weight as AUC and terminal bw $(P<0.001$, for both variables), explaining $21 \%$ of the variation in tumor diameter.

3.12. Long-Term Survival of Untreated ob Mice. For examination of impact of the $o b$ genotype on life-span, groups of untreated $A p c^{\mathrm{Min} /+}$ and $A p c^{+/+}$mice of all three $o b$ genotypes and both genders were kept under regular observation until euthanized ( $n=24-35$ per experimental group). Survival of each genotype of mice was depicted as decreasing \% of surviving mice compared with the number of mice present at the start of the experiment (Figure 7). The life-span was significantly shorter for all three $A p c^{M i n /+} \mathrm{X} o b$ genotypes, because of their intestinal tumors causing anemia and other complications leading to early termination, compared with the $A p c^{+/+} \mathrm{X}$ ob genotypes $(P<0.05$, for all three
TABLE 2: Associations between various parameters for body weight and glucose, insulin and cytokine levels.

\begin{tabular}{lcccccc}
\hline & \multicolumn{2}{c}{ AUC bw } & \multicolumn{2}{c}{ Terminal bw } & \multicolumn{2}{c}{ Terminal BMI } \\
& $R^{2}$ & $P$ & $R^{2}$ & $P$ & $R^{2}$ & $P$ \\
\hline Terminal bw & 0.91 & $<0.001$ & & & & \\
\hline Terminal BMI & 0.59 & $<0.001$ & 0.62 & $<0.001$ & & \\
\hline $\begin{array}{l}\text { Glucose } \\
\text { 6 weeks }\end{array}$ & 0.46 & $<0.001$ & 0.47 & $<0.001$ & 0.57 & $<0.001$ \\
\hline $\begin{array}{l}\text { Glucose } \\
\text { 11 weeks }\end{array}$ & 0.33 & $<0.001$ & 0.33 & $<0.001$ & 0.43 & $<0.001$ \\
\hline Insulin & 0.34 & $<0.001$ & 0.32 & $<0.001$ & 0.48 & $<0.001$ \\
\hline IL-1 $\beta$ & 0.00 & n.s. & 0.00 & n.s. & 0.01 & n.s. \\
\hline TNF $\alpha$ & 0.20 & 0.021 & 0.23 & 0.013 & 0.07 & n.s. \\
\hline Associtin & & & & & & \\
\hline
\end{tabular}

Associations between various parameters for body weight (independent variables) and glucose, insulin, and cytokine levels (dependent variables) were examined with simple linear regression (SigmaPlot 12.3, Systat Software Inc., San Jose, CA, USA). This was performed on pairs of end points from all mice from all experimental groups from which individual data could be paired. Body weight (bw) data were evaluated either as area under the curve from week 3 to 11 (AUC bw), as terminal bw, or as terminal body mass index (BMI) at 11 weeks of age. Nonfasted blood glucose was measured at 6 and 11 weeks of age. Insulin was measured with ELISA, and TNF $\alpha$ was measured with flow cytometer, both in plasma obtained at termination at 11 weeks. $R^{2}=$ coefficient of determination, n.s. = not statistically significant.

comparisons). There were no significant differences between the three $o b$ genotypes either of $A p c^{\mathrm{Min} /+}$ or $A p c^{+/+}$genotype when tested with one-way ANOVA. However, when tested with Student's $t$-test, or Mann-Whitney Rank sum test for data that failed the normality test, the $A p c^{+/+}$ob/ob mice had significantly shorter life-span than the $A p c^{+/+}$wt/wt and $\mathrm{ob} /$ wt mice ( $P \leq 0.001$, for both comparisons), whereas $A p c^{+/+}$ob/wt and wt/wt mice were not significantly different.

\section{Discussion}

In this experiment, we have studied obesity as an end point in itself, and as a factor impacting on intestinal tumorigenesis. The obesity was either caused genetically, that is, by the inherited $o b$ mutation in the lep gene, or caused by an environmental factor, a $45 \%$ fat diet, given from weaning to termination at 11 weeks of age. We have examined the effect of the obesity on both spontaneous intestinal tumors caused by the inherited Min mutation in the Apc gene, and on tumors induced by the mutagenic and carcinogen heterocyclic amine PhIP found in cooked meat and fish.

4.1. Genetically-Induced Obesity. In this experiment, we have evaluated obesity in three different ways: as body weight development using AUC calculated from weaning at 3 weeks to termination at 11 weeks of age, as terminal body weight and terminal BMI. This was done because various indicators of obesity, such as BMI, waist circumference and waist-tohip ratio, waist-height-ratio or percentage of body fat, have been found to be more or less strongly associated with human study end points, and are therefore more or less suitable as indicators of obesity. All the three studied body weight 
TABLE 3: Associations between body weight, glucose, insulin and cytokine levels and the number or diameter of small intestinal tumors.

\begin{tabular}{|c|c|c|c|c|c|}
\hline \multicolumn{3}{|c|}{ Number of small intestinal tumors } & & \multicolumn{2}{|c|}{ Diameter of small intestinal tumors } \\
\hline & $R^{2}$ & $P$ & & $R^{2}$ & $P$ \\
\hline Diameter of tumors & 0.51 & $<0.001$ & No. of tumors & 0.51 & $<0.001$ \\
\hline AUC bw & 0.11 & $<0.001$ & AUC bw & 0.14 & $<0.001$ \\
\hline Terminal bw & 0.05 & $<0.001$ & Terminal bw & 0.07 & $<0.001$ \\
\hline Terminal BMI & 0.08 & $<0.001$ & Terminal BMI & 0.10 & $<0.001$ \\
\hline $\begin{array}{l}\text { Glucose } \\
6 \text { weeks } \\
\end{array}$ & 0.12 & $<0.001$ & $\begin{array}{l}\text { Glucose } \\
6 \text { weeks }\end{array}$ & 0.09 & $<0.001$ \\
\hline $\begin{array}{l}\text { Glucose } \\
11 \text { weeks }\end{array}$ & 0.18 & $<0.001$ & $\begin{array}{l}\text { Glucose } \\
11 \text { weeks }\end{array}$ & 0.08 & $<0.001$ \\
\hline Insulin & 0.03 & n.s. & Insulin & 0.06 & n.s. \\
\hline IL-1 $\beta$ & 0.00 & n.s. & IL-1 $\beta$ & 0.01 & n.s. \\
\hline TNF $\alpha$ & 0.09 & n.s. & TNF $\alpha$ & 0.31 & 0.003 \\
\hline
\end{tabular}

Associations between body weight parameters, glucose, insulin, and cytokine levels (independent variables) and the number or diameter of small intestinal tumors (dependent variables) were examined with simple linear regression (SigmaPlot 12.3, Systat Software Inc., San Jose, CA, USA). This was performed on pairs of end points from all mice from all experimental groups from which individual data could be paired. Number of small intestinal tumors is calculated as number of tumors in each mouse, and tumor diameter is calculated as mean of all tumors in each mouse. Body weight (bw) data were evaluated either as area under the curve from week 3 to 11 (AUC bw), as terminal bw, or as terminal body mass index (BMI) at 11 weeks of age. Nonfasted blood glucose was measured at 6 and 11 weeks of age. Insulin was measured with ELISA, and TNF $\alpha$ was measured with flow cytometer, both in plasma obtained at termination at 11 weeks. $R^{2}=$ coefficient of determination, n.s. = not statistically significant.

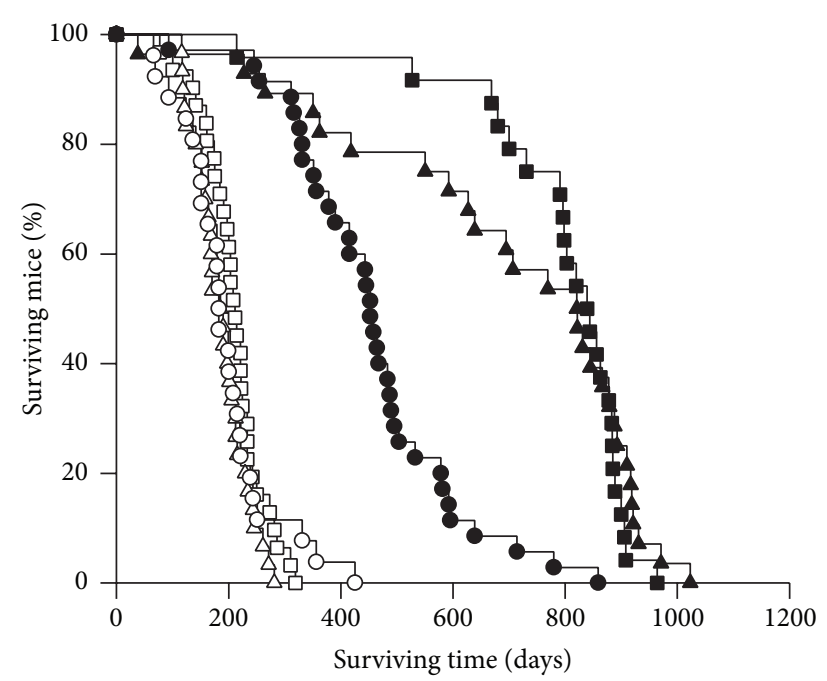

FIGURE 7: Survival of mice. Untreated pooled female and male $A p c^{M i n /+}$ and $A p c^{+/+}$mice of all three $o b$ genotypes were kept under regular observation until euthanized. Survival of each genotype of mice was depicted as decreasing $\%$ of surviving mice compared with the number of mice present at the start of the experiment $\left(n=26,30\right.$ and 31 for groups of $A p c^{M i n /+} X \operatorname{Lep}^{o b / o b}(\bigcirc), A_{p c} c^{M i n /+} X \operatorname{Lep}^{o b / w t}(\triangle)$ and $A p c^{M i n /+} X$ $L e p^{w t / w t}(\square)$ mice, respectively, and $n=35,28$ and 24 for $A p c^{+/+} X L e p^{o b / o b}(\bullet), A p c^{+/+} X L e p^{o b / w t}(\mathbf{\Delta})$ and $A p c^{+/+} X L e p^{w t / w t}(\boldsymbol{\square})$ mice, respectively.

parameters gave more or less the same differences between the experimental groups (Figure 1, data not shown), except that there was no difference in BMI between ob/wt and wt/wt mice. In addition, BMI was higher in ob/ob females than in males, whereas ob/ob males were larger than females for body weight as AUC and terminal body weight.

The mice with a homozygous $o b$ mutation in the lep gene have a deficiency in the hormone leptin. These ob/ob mice were significantly heavier than the ob/wt and wt/wt, independent of body weight parameter (Figure 1, data not shown), reflecting the necessity of the leptin hormone for maintaining normal body weight. However, when we measured the feed intake for $24 \mathrm{~h}$, the ob/ob mice actually had significantly lower intake of $\mathrm{g}$ feed or $\mathrm{kcal} / \mathrm{g}$ bw than ob/wt and wt/wt mice ( $P<0.001$, for both comparisons), whereas ob/wt and wt/wt mice were not significantly different (Table 1). The ob/ob mice have been suggested to become obese because of hyperphagia [12]; however, our data indicate that they become obese despite of eating fewer grams of food and less calories per g body weight. According to information from the breeder [12], the ob/ob mice gain excess weight and deposit excess fat even when restricted to a diet sufficient for normal 
weight maintenance in lean mice. However, lower level of physical activity probably also contributes to the obesity in the ob/ob mice, since leptin is involved in regulation of energy expenditure [11, 13], and we observed that the ob/ob mice were much less physically active than the ob/wt and wt/wt mice.

4.2. Diet-Induced Obesity (DIO). In addition to geneticallyinduced obesity caused by the $o b$ mutation, we also studied the effects of diet-induced obesity (DIO), as an environmental factor, more relevant to the obese condition in most humans. The $45 \%$ fat diet significantly increased obesity, evaluated by all three body weight parameters, compared with the $10 \%$ fat control diet, based on all mice, in both genders, and in most subgroups of mice, except that the AUC for body weight was not significant in the subgroup of female $\mathrm{wt} / \mathrm{wt}$ mice and in the ob/wt mice of both genders (Figure 1, data not shown).

DIO has been defined as a body weight of more than two standard deviations above the average body weight of mice fed a low-fat diet [21]. The ob/ob mice in all experimental groups, except the female $A p c^{M i n /+} \mathrm{X}$ ob/ob mice given $45 \%$ fat diet and PhIP, fulfilled this strict definition, based on terminal bw (data not shown). For $A p c^{\mathrm{Min} /+} \mathrm{X}$ ob/wt or wt/wt, of both genders, given $0.9 \% \mathrm{NaCl}$ or PhIP, the mean in all eight groups was slightly below the body weight defining DIO, whereas for the $A p c^{+/+} \mathrm{X} \mathrm{ob} / \mathrm{wt}$ or wt/wt, of both genders, given $0.9 \% \mathrm{NaCl}$ or PhIP, 5 of 8 experimental groups fulfilled this definition. Except for the female and male $A p c^{+/+} \mathrm{X} \mathrm{ob} / \mathrm{wt}$ given $0.9 \% \mathrm{NaCl}$ and $45 \%$ fat diet, and the male $A p c^{+/+} \mathrm{X}$ $\mathrm{wt} / \mathrm{wt}$ given PhIP and $45 \%$ fat diet, slightly lower body weight can be explained by the fact that $A p c^{\mathrm{Min} /+}$ mice generally have lower body weight than the $\mathrm{Apc}^{+/+}$because of their spontaneous intestinal tumors, affected even further with PhIP [19].

Mice seem to eat a constant amount of calories. Therefore, mice on a high fat diet would have a lower intake of food measured as $\mathrm{g}$ feed compared with mice on a low-fat diet. In this experiment, the mice fed a $45 \%$ fat diet had indeed significantly lower intake of $g$ feed than mice fed the control $10 \%$ fat diet on a body weight basis (Table 1). It would be expected that the intake of the $45 \%$ fat diet was reduced until the same intake of calories was reached as with the $10 \%$ fat diet, but the intake of $\mathrm{kcal} / \mathrm{g}$ bw/day was also significantly lower in the mice given the $45 \%$ fat diet (Table 1). Therefore, the observed difference in body weight between mice on a $10 \%$ fat and a $45 \%$ fat diet seems to be influenced also by the type of diet (i.e., a higher content of fat at expense of carbohydrates) and/or possibly reduced activity of the heavier mice on the $45 \%$ fat diet. The body weight increase was extreme in the ob/ob mice given the $45 \%$ fat diet, and their level of physical activity was noticeably reduced.

The ob/ob mice on a $45 \%$ fat diet also showed transient signs of diabetes, such as increased water intake and urine output, and glucose in the urine, as also described by the breeder [12]. However, there were no signs of the ob/ob mice being more hypothermic than the ob/wt and wt/wt mice, as described [12]. They seemed to thrive on regular temperature $\left(20-24^{\circ} \mathrm{C}\right)$.

A recent paper describing a meta-review of micro-array data on high-fat DIO in C57BL/6J mice found that upregulated genes were associated with fatty acid synthesis, inflammation, signal transduction and transporters, and energy homeostasis [22]. Down-regulated genes were associated with sterol biosynthesis, insulin sensitivity and oxidative stress. Peroxisome proliferator activated receptor (PPAR) $\gamma$ appeared to be a central obesity gene, interacting with lipid metabolism and inflammation genes.

4.3. Intestinal Tumorigenesis. In the $A p c^{\mathrm{Min} /+}$ mice on the C57BL/6J background, the small intestine, rather than the colon, is the main target organ, and we therefore limit our discussion to the small intestinal tumors. In our study, homozygous mutation in the $o b$ gene, causing deficiency in the hormone leptin in the ob/ob mice, significantly increased the number of spontaneous intestinal tumors and the number of PhIP-induced tumors in $A p c^{\mathrm{Min} /+}$ mice compared with the mice having normal (wt/wt) or lower (ob/wt) levels of leptin (Figure 2). The tumor numbers were not significantly different between the ob/wt and wt/wt mice. The $45 \%$ fat diet further increased the number of small intestinal tumors based on all mice, and in the $0.9 \% \mathrm{NaCl}$-treated mice, that is, the spontaneous tumors. After PhIP exposure, the $45 \%$ fat diet did not increase the tumor numbers further based on all mice, and the response varied between the genotypes and genders (Figure 2).

Females and males had the same number of small intestinal tumors (Figure 2), but the tumors were significantly larger in males than in females, based on all mice $(P<0.001)$ and in many of the subgroups (data not shown), indicating a higher susceptibility in males to factors affecting tumor growth. Epidemiological evidence indicates a higher risk in men than in women for colorectal cancer $[23,24]$.

In the ob/ob mice, there were unusually high numbers of small intestinal tumors proximally in the small intestine, which were increased further with a $45 \%$ fat diet (Figure 4). It could be speculated whether this is caused by the increased secretion of bile acid into this small intestinal area caused by the high fat diet, as has been suggested to cause intestinal cancer [25].

The present data showed a consistent relationship between obesity (Figure 1, data not shown) and number of small intestinal tumors (Figure 2), both being increased in the ob/ob mice compared with the ob/wt and wt/wt mice, and the spontaneous tumors being further increased with the $45 \%$ fat diet. The same pattern was also observed in nonfasted blood glucose levels (data not shown). Body weight evaluated as AUC from week 3 to 11, and blood glucose levels at week 6 and week 11, showed the strongest association with number of small intestinal tumors with $11 \%, 12 \%$ and $18 \%$, respectively $(P<0.001$, all values) (Table 3$)$.

In a previous study, similar results as in our study were found by crossing a mouse with a different mutation in the $A p c$ gene $\left(A p c^{1638 N /+}\right)$ with the C57BLKS-mLep ${ }^{d b / d b}$ mice, carrying a mutation in the leptin receptor gene (Ob-Rb) 
causing both obesity and diabetes mellitus [26]. At 6 months of age, these mice had increased numbers of tumors in their small intestine, and also tumors in the stomach, cecum, and colon, which were not seen in the $A p c^{1638 N /+}$ mouse. In another study, the offspring from the crossing of the same Min/+ mouse as we used (C57BL/6J-Apc ${ }^{\mathrm{Min} /+}$ ) and the C57BL/KsJ- $d b / d b$ mouse, also having both obesity and diabetes, had increased number of total and small intestinal adenomas and increased incidence of colonic tumors at 15 months of age [27]. In these two studies, however, DIO was not included.

In humans, overweight and/or obesity are associated with increased risk, seen as increased incidence, mortality or poor prognosis for many types of cancer, including colon cancer [28-31]. Both body fatness and abdominal fatness have been evaluated as convincing increasing risks of colorectal cancer $[32,33]$.

4.4. Three Main Hypotheses for the Association between Obesity and Intestinal Tumorigenesis. There seem to be numerous signaling molecules and pathways through which obesity may impact on cancer, and considerable cross-talk and convergence between the pathways involved, ultimately ending in increased cell proliferation, cell growth or angiogenesis, or reduced apoptosis, and thus tumor promotion or progression. At least three main hypotheses, mutually interconnected, exist for the association between obesity and colorectal cancer [28-31, 34]: (1) obesity has been suggested to be associated with colon cancer via changes in adipokine levels released from the adipose tissues locally or systemically, such as increase in leptin and/or decrease in adiponectin, (2) that disturbed blood glucose regulation observed as increased serum levels of glucose, insulin and IGF-1 and insulin resistance lead to increased proliferation and reduced apoptosis, ultimately causing cancer, (3) or that obesity is a chronic low-grade inflammatory state in the adipose tissues releasing numerous proinflammatory cytokines, such as TNF $\alpha$, IL-6 and IL- $1 \beta$, affecting cancer. In addition, steroid hormones such as estrogen and androgen may be involved, but their role in colon cancer is controversial.

Regarding the first hypothesis of changes in adipokine levels as the link between obesity and colon cancer, we investigated the influence of leptin by the use of leptindeficient mice. The diameter of the small intestinal tumors was significantly higher in all ob/ob mice compared with $\mathrm{ob} / \mathrm{wt}$ and wt/wt mice $(P<0.001$, for both comparisons) (Figure 3, data not shown); thus, the obesity increased the tumor size in spite of lack of growth-promoting leptin, in the $\mathrm{ob} / \mathrm{ob}$ mice. As opposed to the ob/ob mouse, common obesity in humans is characterized not by lack of leptin, but rather by elevated levels of plasma leptin correlated with fat mass and BMI, representing a form of leptin resistance $[35,36]$.

However, the causative role of increased leptin in colon cancer is controversial and the data contradictory. Dysregulation of leptin or its receptors may contribute to colon cancer via effects on growth and proliferation of cancer cells via activation of signaling pathways, including JAK/STAT, PI3-kinase/AKT, and/or MAP kinases [37]. Leptin stimulated proliferation of human colon cancer cells in vitro and in rat colon [38] and promoted motility and invasiveness of human colon cancer cell lines [39], but had either potentiating or inhibiting effect on growth of human cancer cells from various other organs in vitro [40]. Leptin reduced the development of aberrant crypt foci (ACF), precancerous lesions in rat colon mucosa, induced by the carcinogen azoxymethane (AOM) [41], and leptin was found not to be a promotor in development of ACF in the colons of ob/ob and $\mathrm{db} / \mathrm{db}$ mice [42]. Others found that leptin acts as a growth factor for colorectal tumors after initiation with AOM in mice [43].

In our experiment, the dietary fat is not affecting tumor growth as such, since the diameter of the small intestinal tumors was not significantly higher in mice on a $45 \%$ fat diet compared with the $10 \%$ fat diet, based on all mice. Some statistically significant differences were observed in the various subgroups, but the differences were not consistent in direction with regard to $\%$ fat diet. However, both female and male ob/ob mice had significantly smaller tumors after a $45 \%$ fat diet compared with a $10 \%$ fat diet $(P<0.001$, for both comparisons), possibly indicating formation of new tumors (Figures 3(a) and 3(b), data not shown). It could be speculated that lipotoxic free fatty acids from the $45 \%$ fat diet $[28,44,45]$, and/or the subsequent obesity [46], cause oxidative stress and accumulation of reactive oxygen species (ROS), which may lead to DNA damage and tumor initiation in the intestines. Genes involved in lipid metabolism, phospholipase A2, phospholipase $\mathrm{C} \varepsilon$ and phospholipase $\mathrm{D}$, have been shown to modulate the intestinal tumor numbers by interacting with the Wnt signaling pathway [47-49]. However, controversy exists regarding the association between dietary animal fat as such and human colon cancer [50]. It may be that other factors than fat in the diet, such as heme iron in meat or carcinogens produced by cooking of meat, or the total energy, are also important for colon cancer.

The second hypothesis suggests that disturbed blood glucose regulation may lead to increased proliferation and reduced apoptosis, ultimately causing cancer. In our dynamic assessment of glucose regulation using GTT, ob/ob mice showed a much slower decrease in blood glucose than both ob/wt and wt/wt mice $(P<0.001$, for both comparisons) (Figure 5). The nonfasted blood glucose levels were also significantly higher in ob/ob mice compared with both ob/wt and wt/wt mice at both 6 and 11 weeks $(P<0.001$ for all comparisons) (data not shown), whereas there was no difference between ob/wt and wt/wt mice, following the same pattern as genetically induced-obesity.

Mice on a $45 \%$ fat diet had a slower blood glucose decrease after challenge in GTT than mice on a $10 \%$ fat $\operatorname{diet}(P<0.001)$ (Figure 5). This was also observed in the subgroups ob/ob mice, ob/wt mice and wt/wt mice $(P<$ 0.001 , for all comparisons). The AUC in GTT was remarkably large in the ob/ob mice on a $45 \%$ fat diet (Figure 5), demonstrating a markedly reduced ability to regulate blood glucose. Nonfasted blood glucose levels were also significantly higher in all mice on a $45 \%$ fat diet compared with a $10 \%$ fat diet at both age 6 and 11 weeks $(P<0.001$, for both comparisons) (data not shown). 
The ob/ob mice had significantly higher levels of insulin than mice with ob/wt or wt/wt genotypes, based on all mice $(P<0.001$, for both comparisons) (Figures 6(a) and 6(b)). The ob/wt and wt/wt mice were not significantly different. There were no significant differences in insulin levels between mice on a $10 \%$ or a $45 \%$ fat diet. However, the effect of the fat diets on insulin levels should be interpreted with caution because of the low number of samples, especially from mice on a $10 \%$ fat diet.

Overweight and obesity may cause secondary changes such as hyperglycemia, hyperinsulinemia and insulin resistance, and type 2 diabetes, which may lead to cancer development $[34,51,52]$. The hyperinsulinemia may enhance synthesis of insulin-like growth factor 1 (IGF-1) and its bioavailability by decreasing the IGF binding proteins (IGFBP) $[53,54]$. It is thought that macrophage-related inflammatory activities in white adipose tissue (WAT) may contribute to obesityinduced insulin resistance $[55,56]$. Leptin can affect insulin and glucose metabolism [57]. Studies have shown that both a lack of leptin signals and adiposity as such may contribute to insulin resistance and that decrease in central leptin signaling can critically affect glucose metabolism in obese mice [58].

An overall increase in glucose by age 20 weeks versus 6 weeks reported in the wild-type C57BL/6J mouse [59] was not clearly observed in our mice, since the glucose levels varied with the genotypes; significantly higher at week 11 versus week 6 in ob/wt mice $(P=0.017)$ or in the same direction but nonsignificant in $A p c^{\mathrm{Min} /+}$ mice and wt/wt mice, whereas higher levels were seen at week 6 compared with week 11 in $A p c^{+/+}$mice $(P<0.001)$ and in the ob/ob mice $(P<0.001)$. Hence, the genotypes, as well as the fat diets and/or the PhIP treatment, affected these results.

We observed a higher level of nonfasted blood glucose in male ob/wt and wt/wt mice compared with females both at age 6 and 11 weeks (data not shown). The same tendency was seen in the GTT. This gender difference is in accordance with reference values of blood glucose in the wild-type C57BL/6J mouse obtained both at 6 and 20 weeks of age [59]. However, as opposed to the normal wild-type mice, the female ob/ob mice had higher glucose levels than the males.

The $A p c^{M i n /+}$ mice had significantly higher nonfasted blood glucose levels than $A p c^{+/+}$mice at 11 weeks $(P<0.001)$ (data not shown). This was not caused by higher feed intake since there were no significant differences in feed intake between $A p c^{\mathrm{Min} /+}$ and $A p c^{+/+}$mice (Table 1), and the body weight was lower in $A p c^{\mathrm{Min} /+}$ mice than $A p c^{+/+}$mice for all three body weight scores (Figure 1, data not shown). A possible explanation is that APC is involved in regulation of epithelial glucose transport in the intestines, since $A p c^{\mathrm{Min} /+}$ mice had increased activity of the electrogenic glucose carrier (SGLT1) compared with $A p c^{+/+}$mice [60]. Apc is a component of the Wnt signaling pathway $[5,6]$. Therefore, other intriguing possibilities of a relationship between $A p c$ and blood glucose levels come from data showing that the Wnt signaling pathway, which is as an important modulator of adipocyte differentiation $[61,62]$, also influences endocrine pancreas development and modulates mature $\beta$-cell functions including insulin secretion, survival and proliferation, and thereby may be involved in the pathogenesis of diabetes [63]. Components of the Wnt signaling pathway may also be involved in determining susceptibility to DIO [64].

The percentage of the variation in the blood glucose levels at 6 weeks that could be explained by the body weight data was $46-57 \%$, and at 11 weeks it was $33-43 \%$, depending on which parameter was used for body weight $(P<0.001$, for all comparisons) (Table 2 ). The percentage of the variation in the insulin levels that could be explained by the body weight data was $32-48 \%$, depending on which parameter was used for body weight ( $P<0.001$, for all comparisons) (Table 2 ). Body weight therefore seems to have a moderate effect on blood glucose regulation.

Overall, the increase in body weight (Figure 1) and the increased and prolonged blood glucose levels (Figure 5) correlate well with the increased number of small intestinal tumors (Figure 2).

In an epidemiological study, elevated insulin and glucose were associated with increased risk of colorectal adenoma and decreased apoptosis in normal rectal mucosa, indicating that insulin may act early in the adenoma-carcinoma sequence to promote the development of colorectal adenoma by decreasing apoptosis [65]. However, a diet high in foods that increased postprandial insulin levels did not increase the risk of colorectal cancer in a large prospective epidemiological study [66].

In the third hypothesis, inflammation has been suggested to be a causative link between obesity and colorectal cancer [28-31, 34]. There are two types of evidence indicating obesity as a chronic inflammatory illness: the release of proinflammatory cytokines such as TNF $\alpha$, IL- 6 and IL-1 $\beta$ from adipose tissues and infiltration of macrophages into the WAT [67]. In our study, we found a significantly higher level of TNF $\alpha$ in ob/ob mice compared with ob/wt and wt/wt mice, based on all mice, and in the subgroup of mice given a $45 \%$ fat diet, but not in the mice given a $10 \%$ fat diet (Figure $6(\mathrm{~d})$ ). The effect of the diets on TNF $\alpha$ should be interpreted with caution because of the low number of samples from mice on a $10 \%$ fat diet. The body weight data AUC and terminal body weight could explain around $20 \%$ of the variation in TNF $\alpha$ levels ( $P=0.021$ and $P=0.013$, resp.) (Table 2$)$. The variation in the number of small intestinal tumors could not be explained by the TNF $\alpha$ levels, whereas $31 \%$ of the variation in the diameter of small intestinal tumors could be explained by the TNF $\alpha$ levels $(P=0.003)$ (Table 3$)$. Thus, our data support that inflammation is associated with obesity and the size of small intestinal tumors.

After diet-induced obesity (60\% fat diet) in C57BL/6 mice, increased expression in the colon of TNF $\alpha$ was found, which instigated alterations in several components of the Wnt signaling pathway leading to tumor transformation [68]. In a model with tumors induced by AOM and dextran sulfate sodium (DSS) in lean (C57BL6/J) and ob/ob mice, it was shown that when pathways involving TNF $\alpha$ were inhibited, tumor numbers and proliferation and apoptosis profiles were returned to levels observed in lean mice [69]. By looking at the temporal sequence of inflammation in relation to tumorigenesis in $\mathrm{Min} /+$ mice, it was found that the increased mRNA expression of the inflammatory cytokines 
TNF $\alpha$, IL-6, IL-1 $\beta$ and monocyte chemoattractant protein 1 (MCP-1) occurred at age 12 weeks in association with a rapid increase in tumor number at the same time, and that, in general, the overall tumor number and abundance of large tumors were positively correlated with the inflammatory cytokine responses [70]. Mice lacking $\mathrm{TNF} \alpha$ because of a targeted null mutation were protected from insulin resistance caused by DIO or the ob/ob mutation [71]. However, a recent review and meta-analysis of epidemiological studies found no associations between colorectal cancer and TNF $\alpha$ and IL-6 [72].

We found no significant differences in TNF $\alpha$ levels between mice exposed to $0.9 \% \mathrm{NaCl}$ or PhIP (Figure 6(d)). Also in rats, it was shown that inflammation did not precede or accompany the induction of preneoplastic lesions in the colon by PhIP [73].

4.5. Effects of Heterozygous ob Mutation. In our experiment, the ob/wt mice were significantly heavier than wt/wt mice when the body weight was evaluated as AUC (Figure 1) and as terminal bw (data not shown), but not as terminal BMI (data not shown). However, feed intake (Table 1), number (Figure 2) and size (Figure 3, data not shown) of small intestinal tumors, GTT results (Figure 5), nonfasted blood glucose levels (data not shown), insulin (Figures 6(a) and 6(b)) and TNF $\alpha$ (Figure 6(d)) levels were not significantly different between the ob/wt and wt/wt mice. Obviously, the heterozygous state of the $o b$ mutation in mice was able to increase the body weight but was not severe enough to negatively affect other end points, including intestinal cancer.

Others have also shown that the ob/wt mice partially display the phenotype of the homozygous ob/ob mice, with approximately $33 \%$ reduction in plasma leptin level when adjusted for fat mass and $24 \%$ increase in percentage of body fat adjusted for age and sex [74]. The homozygous condition of ob/ob is found also in humans and is characterized by very low leptin levels and severe obesity [75]. This genetic condition is too rare to account for the recent obesity epidemic. It is more likely that most cases of common obesity in humans are caused by heterozygosity at several genetic loci for alleles with subtle effects on gene expression and function rather than by major functional disruption of any single gene. However, humans heterozygous for $o b$ also have lower leptin levels and increased body fat percentage relative to wild-type relatives [76].

4.6. Survival. In our experiment, all $A p c^{\mathrm{Min} /+}$ mice had reduced life-spans, due to anemia or other complications such as rectal prolapse, caused by the spontaneous intestinal tumors induced by the mutated $A p c$ gene (Figure 7). Among these mice which have a limited life-span because of their tumors, the $o b / o b$ genotype did not affect survival. However, in the $A p c^{+/+}$mice being able to live out their natural lifespan, the ob/ob mice had significantly shorter lives compared with ob/wt and wt/wt mice (Figure 7). The life-span was not significantly different between the $A p c^{+/+}$ob/wt and wt/wt mice in our experiment, which was also reported by others, despite increased body weight and decreased leptin levels [74].

\section{Conclusions}

We have studied obesity induced both genetically via the $o b$ mutation and via a $45 \%$ fat diet and shown that the high fat diet severely exacerbates the inherited obesity. In mice both with genetically-induced obesity and exposed to a $45 \%$ fat diet, spontaneous intestinal tumorigenesis was increased. The carcinogen- (PhIP-) induced intestinal tumorigenesis was not further increased by a $45 \%$ fat diet. Hyperglucosemia and insulinemia, indicating disturbed glucose regulation, and inflammation as seen by increased TNF $\alpha$ levels, were found associated with the obesity, implicating these as possible mechanisms involved in the association between obesity and intestinal tumorigenesis. The genetically-induced obesity decreased the life-span of the ob/ob mice.

\section{Conflict of Interests}

The authors declare that there is no conflict of interests regarding the publication of this paper.

\section{Acknowledgments}

This work was supported by The Research Council of Norway, Project no. 196112/H10 (H. T. Ngo and I.-L. Steffensen). The authors thank Hege Hjertholm, Tone Rasmussen and Hildegunn Dahl for excellent technical assistance with PCR genotyping and practical work with the mice, and Åse Eikeset and Else-Carin Groeng for assistance with the CBA and ELISA assays. Victor Labay Ong is thanked for help with mouse care.

\section{References}

[1] The Organisation for Economic Co-operation and Development (OECD), Health at a Glance 2013, OECD Indicators, OECD, 2013, http://www.oecd.org/els/health-systems/ Health-at-a-Glance-2013.pdf.

[2] Cancer Registry of Norway, Cancer in Norway 2012. CancerIncidence, Mortality, Survival and Prevalence in Norway, Cancer Registry of Norway, Oslo, Norway, 2014, http://www .kreftregisteret.no/Global/Cancer\%20in\%20Norway/2012/CIN _2012.pdf.

[3] A. R. Moser, H. C. Pitot, and W. F. Dove, "A dominant mutation that predisposes to multiple intestinal neoplasia in the mouse," Science, vol. 247, no. 4940, pp. 322-324, 1990.

[4] L.-K. Su, K. W. Kinzler, B. Vogelstein et al., "Multiple intestinal neoplasia caused by a mutation in the murine homolog of the APC gene," Science, vol. 256, no. 5057, pp. 668-670, 1992.

[5] B. M. Boman and J. Z. Fields, "An APC:WNT counter-currentlike mechanism regulates cell division along the human colonic crypt axis: a mechanism that explains how APC mutations induce proliferative abnormalities that drive colon cancer development," Frontiers in Oncology, vol. 3, Article ID 244, 2013.

[6] S. Nelson and I. S. Näthke, "Interactions and functions of the adenomatous polyposis coli (APC) protein at a glance," Journal of Cell Science, vol. 126, no. 4, pp. 873-877, 2013.

[7] E. R. Fearon, "Molecular genetics of colorectal cancer," The Annual Review of Pathology: Mechanisms of Disease, vol. 6, pp. 479-507, 2011. 
[8] S. Al-Sohaily, A. Biankin, R. Leong, M. Kohonen-Corish, and J. Warusavitarne, "Molecular pathways in colorectal cancer," Journal of Gastroenterology and Hepatology, vol. 27, no. 9, pp. 1423-1431, 2012.

[9] A. M. Ingalls, M. M. Dickie, and G. D. Snell, "Obese, a new mutation in the house mouse," The Journal of Heredity, vol. 41, no. 12, pp. 317-318, 1950.

[10] Y. Zhang, R. Proenca, M. Maffei, M. Barone, L. Leopold, and J. M. Friedman, "Positional cloning of the mouse obese gene and its human homologue," Nature, vol. 372, no. 6505, pp. 425-432, 1994.

[11] F. F. Chehab, J. Qiu, and S. Ogus, "The use of animal models to dissect the biology of leptin," Recent Progress in Hormone Research, vol. 59, pp. 245-266, 2004.

[12] The Jackson Laboratory, JAX Mice Database-000632 B6.Cg$\operatorname{Lep}^{o b} / J$, The Jackson Laboratory, 2014, http://jaxmice.jax.org/ strain/000632.html.

[13] J. M. Friedman and J. L. Halaas, "Leptin and the regulation of body weight in mammals," Nature, vol. 395, no. 6704, pp. 763770,1998 .

[14] H. A. J. Schut and E. G. Snyderwine, "DNA adducts of heterocyclic amine food mutagens: implications for mutagenesis and carcinogenesis," Carcinogenesis, vol. 20, no. 3, pp. 353-368, 1999.

[15] I.-L. Steffensen, J. E. Paulsen, T. J. Eide, and J. Alexander, "2-Amino-1-methyl-6-phenylimidazo[4,5-b]pyridine increases the numbers of tumors, cystic crypts and aberrant crypt foci in multiple intestinal neoplasia mice," Carcinogenesis, vol. 18, no. 5, pp. 1049-1054, 1997.

[16] J. E. Paulsen, I.-L. Steffensen, Å. Andreassen, R. Vikse, and J. Alexander, "Neonatal exposure to the food mutagen 2-amino1-methyl-6-phenylimidazo[4,5-b]pyridine via breast milk or directly induces intestinal tumors in multiple intestinal neoplasia mice," Carcinogenesis, vol. 20, no. 7, pp. 1277-1282, 1999.

[17] I.-L. Steffensen, H. A. J. Schut, J. E. Paulsen, Å. Andreassen, and J. Alexander, "Intestinal tumorigenesis in multiple intestinal neoplasia mice induced by the food mutagen 2-amino-1methyl-6-phenylimidazo[4,5- $b]$ pyridine: perinatal susceptibility, regional variation, and correlation with DNA adducts," Cancer Research, vol. 61, no. 24, pp. 8689-8696, 2001.

[18] A. R. Moser, A. R. Shoemaker, C. S. Connelly et al., "Homozygosity for the Min allele of Apc results in disruption of mouse development prior to gastrulation," Developmental Dynamics, vol. 203, no. 4, pp. 422-433, 1995.

[19] H. T. Ngo, R. B. Hetland, A. Sabaredzovic, L. S. Haug, and I.-L. Steffensen, "In utero exposure to perfluorooctanoate (PFOA) or perfluorooctane sulfonate (PFOS) did not increase body weight or intestinal tumorigenesis in multiple intestinal neoplasia (Min/+) mice," Environmental Research, vol. 132, pp. 251-263, 2014.

[20] World Health Organization, Definition and Diagnosis of Diabetes Mellitus and Intermediate Hyperglycemia: Report of a WHO/IDF Consultation, WHO, Geneva, Switzerland, 2006, http://whqlibdoc.who.int/publications/2006/9241594934_eng .pdf.

[21] K. El-Haschimi and H. Lehnert, "Leptin resistance-or why leptin fails to work in obesity," Experimental and Clinical Endocrinology and Diabetes, vol. 111, no. 1, pp. 2-7, 2003.

[22] E. Kim, E. J. Kim, S.-W. Seo, C.-G. Hur, R. A. McGregor, and M.-S. Choi, "Meta-review of protein network regulating obesity between validated obesity candidate genes in the white adipose tissue of high-fat diet-induced obese C57BL/6J mice," Critical
Reviews in Food Science and Nutrition, vol. 54, no. 7, pp. 910923, 2014.

[23] I. Laake, I. Thune, R. Selmer, S. Tretli, M. L. Slattery, and M. B. Veierød, "A prospective study of body mass index, weight change, and risk of cancer in the proximal and distal colon," Cancer Epidemiology Biomarkers \& Prevention, vol. 19, no. 6, pp. 1511-1522, 2010.

[24] Z. Levi, J. D. Kark, M. Barchana et al., "Measured body mass index in adolescence and the incidence of colorectal cancer in a cohort of 1.1 million males," Cancer Epidemiology Biomarkers \& Prevention, vol. 20, no. 12, pp. 2524-2531, 2011.

[25] H. Ajouz, D. Mukherji, and A. Shamseddine, "Secondary bile acids: an underrecognized cause of colon cancer," World Journal of Surgical Oncology, vol. 12, no. 1, article 164, 2014.

[26] C. Gravaghi, J. Bo, K. M. D. LaPerle et al., "Obesity enhances gastrointestinal tumorigenesis in Apc-mutant mice," International Journal of Obesity, vol. 32, no. 11, pp. 1716-1719, 2008.

[27] K. Hata, M. Kubota, M. Shimizu et al., "C57Bl/KsJ- $d b / d b-$ $A p c^{M i n /+}$ mice exhibit an increased incidence of intestinal neoplasms," International Journal of Molecular Sciences, vol. 12, no. 11, pp. 8133-8145, 2011.

[28] M. J. Khandekar, P. Cohen, and B. M. Spiegelman, "Molecular mechanisms of cancer development in obesity," Nature Reviews Cancer, vol. 11, no. 12, pp. 886-895, 2011.

[29] P. L. Prieto-Hontoria, P. Pérez-Matute, M. Fernández-Galilea, M. Bustos, J. A. Martínez, and M. J. Moreno-Aliaga, "Role of obesity-associated dysfunctional adipose tissue in cancer: a molecular nutrition approach," Biochimica et Biophysica Acta, vol. 1807, no. 6, pp. 664-678, 2011.

[30] C. R. Guffey, D. Fan, U. P. Singh, and E. A. Murphy, "Linking obesity to colorectal cancer: recent insights into plausible biological mechanisms," Current Opinion in Clinical Nutrition and Metabolic Care, vol. 16, no. 5, pp. 595-600, 2013.

[31] S. D. Hursting, "Obesity, energy balance, and cancer: a mechanistic perspective," in Advances in Nutrition and Cancer, V. Zappia, S. Panico, G. L. Russo, A. Budillon, and F. D. Ragione, Eds., vol. 159 of Cancer Treatment and Research, pp. 21-33, Springer, Berlin, Germany, 2014.

[32] World Cancer Research Fund/American Institute for Cancer Research, Food, Nutrition, Physical Activity and the Prevention of Cancer: A Global Perspective, World Cancer Research Fund/American Institute for Cancer Research, Washington, DC, USA, 2007, http://www.dietandcancerreport.org/cancer_ resource_center/downloads/Second_Expert_Report_full.pdf.

[33] World Cancer Research Fund/American Institute for Cancer Research, Continuous Update Project Report. Food, Nutrition, Physical Activity, and the Prevention of Colorectal Cancer, World Cancer Research Fund/American Institute for Cancer Research, Washington, DC, USA, 2011, http://www.dietandcancerreport .org/cancer_resource_center/downloads/cu/Colorectal-Cancer2011-Report.pdf.

[34] H. Kwon and J. E. Pessin, "Adipokines mediate inflammation and insulin resistance," Frontiers in Endocrinology, vol. 4, article 71, 2013.

[35] C. H. Jung and M.-S. Kim, "Molecular mechanisms of central leptin resistance in obesity," Archives of Pharmacal Research, vol. 36, no. 2, pp. 201-207, 2013.

[36] Y. Zhou and L. Rui, "Leptin signaling and leptin resistance," Frontiers of Medicine, vol. 7, no. 2, pp. 207-222, 2013.

[37] S. Uddin, A. R. Hussain, O. S. Khan, and K. S. Al-Kuraya, "Role of dysregulated expression of leptin and leptin receptors 
in colorectal carcinogenesis," Tumor Biology, vol. 35, no. 2, pp. 871-879, 2014.

[38] Z. Liu, T. Uesaka, H. Watanabe, and N. Kato, "High fat diet enhances colonic cell proliferation and carcinogenesis in rats by elevating serum leptin," International Journal of Oncology, vol. 19, no. 5, pp. 1009-1014, 2001.

[39] T. Jaffe and B. Schwartz, "Leptin promotes motility and invasiveness in human colon cancer cells by activating multiple signaltransduction pathways," International Journal of Cancer, vol. 123, no. 11, pp. 2543-2556, 2008.

[40] P. Somasundar, A. K. Yu, L. Vona-Davis, and D. W. McFadden, "Differential effects of leptin on cancer in vitro," Journal of Surgical Research, vol. 113, no. 1, pp. 50-55, 2003.

[41] T. Aparicio, S. Guilmeau, H. Goiot et al., "Leptin reduces the development of the initial precancerous lesions induced by azoxymethane in the rat colonic mucosa," Gastroenterology, vol. 126, no. 2, pp. 499-510, 2004.

[42] K. N. Ealey, S. Lu, and M. C. Archer, "Development of aberrant crypt foci in the colons of $o b / o b$ and $d b / d b$ mice: evidence that leptin is not a promoter," Molecular Carcinogenesis, vol. 47, no. 9, pp. 667-677, 2008.

[43] H. Endo, K. Hosono, T. Uchiyama et al., "Leptin acts as a growth factor for colorectal tumours at stages subsequent to tumour initiation in murine colon carcinogenesis," Gut, vol. 60, no. 10, pp. 1363-1371, 2011.

[44] J. Garbarino and S. L. Sturley, "Saturated with fat: new perspectives on lipotoxicity," Current Opinion in Clinical Nutrition and Metabolic Care, vol. 12, no. 2, pp. 110-116, 2009.

[45] H. J. Renaud, J. Y. Cui, H. Lu, and C. D. Klaassen, "Effect of diet on expression of genes involved in lipid metabolism, oxidative stress, and inflammation in mouse liver-insights into mechanisms of hepatic steatosis," PLoS ONE, vol. 9, no. 2, Article ID e88584, 2014.

[46] H. K. Vincent, K. E. Innes, and K. R. Vincent, "Oxidative stress and potential interventions to reduce oxidative stress in overweight and obesity," Diabetes, Obesity and Metabolism, vol. 9, no. 6, pp. 813-839, 2007.

[47] A. J. M. Watson and R. N. DuBois, "Lipid metabolism and APC: implications for colorectal cancer prevention," The Lancet, vol. 349, no. 9050, pp. 444-445, 1997.

[48] M. Li, H. Edamatsu, R. Kitazawa, S. Kitazawa, T. Kataoka, and M. Li, "Phospholipase $C \varepsilon$ promotes intestinal tumorigenesis of $A p c^{\mathrm{Min} /+}$ mice through augmentation of inflammation and angiogenesis," Carcinogenesis, vol. 30, no. 8, pp. 1424-1432, 2009.

[49] D. W. Kang, K.-Y. Choi, and D. S. Min, "Phospholipase D meets Wnt signaling: a new target for cancer therapy," Cancer Research, vol. 71, no. 2, pp. 293-297, 2011.

[50] W. C. Willett, "Dietary fat intake and cancer risk: a controversial and instructive story," Seminars in Cancer Biology, vol. 8, no. 4, pp. 245-253, 1998.

[51] I. F. Godsland, "Insulin resistance and hyperinsulinaemia in the development and progression of cancer," Clinical Science, vol. 118 , no. 5, pp. 315-332, 2010.

[52] V. T. Samuel and G. I. Shulman, "Mechanisms for insulin resistance: common threads and missing links," Cell, vol. 148, no. 5, pp. 852-871, 2012.

[53] M. Pollak, "Insulin and insulin-like growth factor signalling in neoplasia," Nature Reviews Cancer, vol. 8, no. 12, pp. 915-928, 2008.

[54] J. Gao, Y. S. Chang, B. Jallal, and J. Viner, "Targeting the insulinlike growth factor axis for the development of novel therapeutics in oncology," Cancer Research, vol. 72, no. 1, pp. 3-12, 2012.
[55] H. Xu, G. T. Barnes, Q. Yang et al., "Chronic inflammation in fat plays a crucial role in the development of obesity-related insulin resistance," The Journal of Clinical Investigation, vol. 112, no. 12, pp. 1821-1830, 2003.

[56] S. E. Shoelson, L. Herrero, and A. Naaz, "Obesity, inflammation, and insulin resistance," Gastroenterology, vol. 132, no. 6, pp. 2169-2180, 2007.

[57] M. Amitani, A. Asakawa, H. Amitani, and A. Inui, "The role of leptin in the control of insulin-glucose axis," Frontiers in Neuroscience, vol. 7, article 51, 2013.

[58] A. M. van den Hoek, B. Teusink, P. J. Voshol, L. M. Havekes, J. A. Romijn, and H. Pijl, "Leptin deficiency per se dictates body composition and insulin action in ob/ob mice," Journal of Neuroendocrinology, vol. 20, no. 1, pp. 120-127, 2008.

[59] X. Zhou and G. K. Hansson, "Effect of sex and age on serum biochemical reference ranges in C57BL/6J mice," Comparative Medicine, vol. 54, no. 2, pp. 176-178, 2004.

[60] R. Rexhepaj, A. Rotte, S. Gu et al., "Tumor suppressor gene adenomatous polyposis coli downregulates intestinal transport," Pflugers Archiv-European Journal of Physiology, vol. 461, no. 5, pp. 527-536, 2011.

[61] S. E. Ross, N. Hemati, K. A. Longo et al., "Inhibition of adipogenesis by Wnt signaling," Science, vol. 289, no. 5481, pp. 950-953, 2000.

[62] C. N. Bennett, S. E. Ross, K. A. Longo et al., "Regulation of Wnt signaling during adipogenesis," The Journal of Biological Chemistry, vol. 277, no. 34, pp. 30998-31004, 2002.

[63] H. J. Welters and R. N. Kulkarni, "Wnt signaling: relevance to $\beta$-cell biology and diabetes," Trends in Endocrinology and Metabolism, vol. 19, no. 10, pp. 349-355, 2008.

[64] R. A. Koza, L. Nikonova, J. Hogan et al., "Changes in gene expression foreshadow diet-induced obesity in genetically identical mice," PLoS genetics, vol. 2, no. 5, article e81, 2006.

[65] T. O. Keku, P. K. Lund, J. Galanko, J. G. Simmons, J. T. Woosley, and R. S. Sandler, "Insulin resistance, apoptosis, and colorectal adenoma risk," Cancer Epidemiology, Biomarkers \& Prevention, vol. 14, no. 9, pp. 2076-2081, 2005.

[66] Y. Bao, K. Nimptsch, J. A. Meyerhardt et al., "Dietary insulin load, dietary insulin index, and colorectal cancer," Cancer Epidemiology, Biomarkers \& Prevention, vol. 19, no. 12, pp. 30203026, 2010.

[67] R. Cancello and K. Clément, "Is obesity an inflammatory illness? Role of low-grade inflammation and macrophage infiltration in human white adipose tissue," BJOG: An International Journal of Obstetrics and Gynaecology, vol. 113, no. 10, pp. 11411147, 2006.

[68] Z. Liu, R. S. Brooks, E. D. Ciappio et al., "Diet-induced obesity elevates colonic TNF- $\alpha$ in mice and is accompanied by an activation of Wnt signaling: A mechanism for obesity-associated colorectal cancer," Journal of Nutritional Biochemistry, vol. 23, no. 10, pp. 1207-1213, 2012.

[69] M. B. S. Flores, G. Z. Rocha, D. M. Damas-Souza et al., "Obesity-induced increase in tumor necrosis factor- $\alpha$ leads to development of colon cancer in mice," Gastroenterology, vol. 143, no. 3, pp. 741-753, 2012.

[70] J. L. McClellan, J. M. Davis, J. L. Steiner et al., "Intestinal inflammatory cytokine response in relation to tumorigenesis in the $A p c^{\mathrm{Min} /+}$ mouse," Cytokine, vol. 57, no. 1, pp. 113-119, 2012.

[71] K. T. Uysal, S. M. Wiesbrock, M. W. Marino, and G. S. Hotamisligil, "Protection from obesity-induced insulin resistance in mice lacking TNF- $\alpha$ function," Nature, vol. 389, no. 6651, pp. 610-614, 1997. 
[72] R. K. Joshi and S.-A. Lee, "Obesity related adipokines and colorectal cancer: a review and meta-analysis," Asian Pacific Journal of Cancer Prevention, vol. 15, no. 1, pp. 397-405, 2014.

[73] D. Kühnel, F. Taugner, B. Scholtka, and P. Steinberg, "Inflammation does not precede or accompany the induction of preneoplastic lesions in the colon of 2-amino-1-methyl-6phenylimidazo[4,5-b]pyridine-fed rats," Archives of Toxicology, vol. 83, no. 8, pp. 763-768, 2009.

[74] W. K. Chung, K. Belfi, M. Chua et al., "Heterozygosity for Lep ${ }^{o b}$ or Lepr ${ }^{d b}$ affects body composition and leptin homeostasis in adult mice," The American Journal of Physiology-Regulatory Integrative and Comparative Physiology, vol. 274, no. 4, pp. R985-R990, 1998.

[75] C. T. Montague, I. S. Farooqi, J. P. Whitehead et al., "Congenital leptin deficiency is associated with severe early-onset obesity in humans," Nature, vol. 387, no. 6636, pp. 903-908, 1997.

[76] I. S. Farooqi, J. M. Keogh, S. Kamath et al., "Partial leptin deficiency and human adiposity," Nature, vol. 414, no. 6859, pp. 34-35, 2001. 


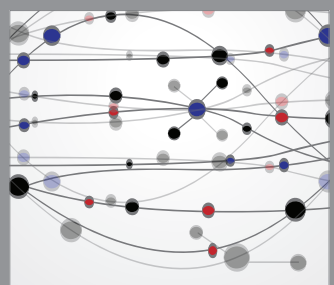

The Scientific World Journal
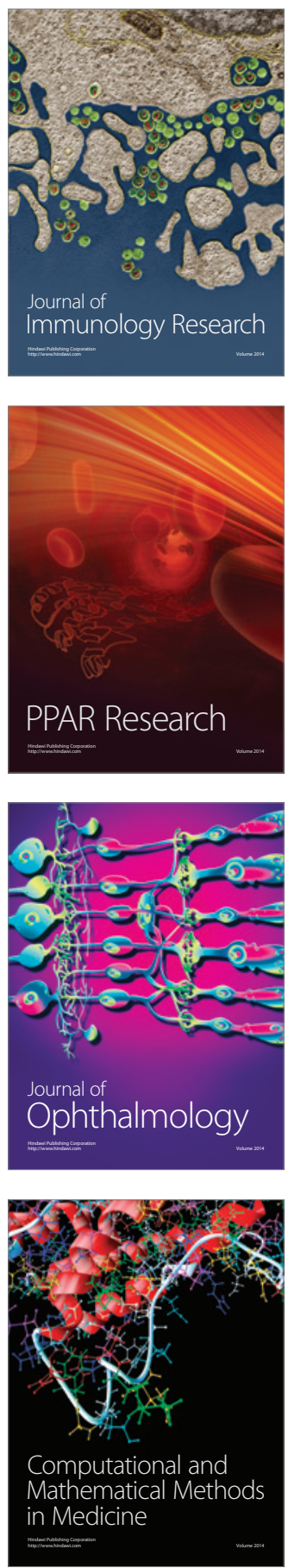

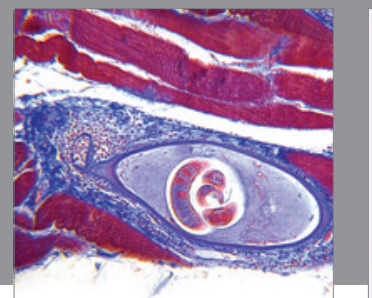

Gastroenterology

Research and Practice
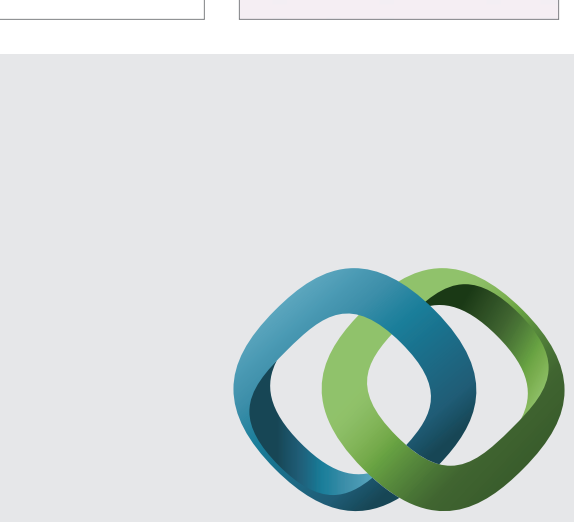

\section{Hindawi}

Submit your manuscripts at

http://www.hindawi.com
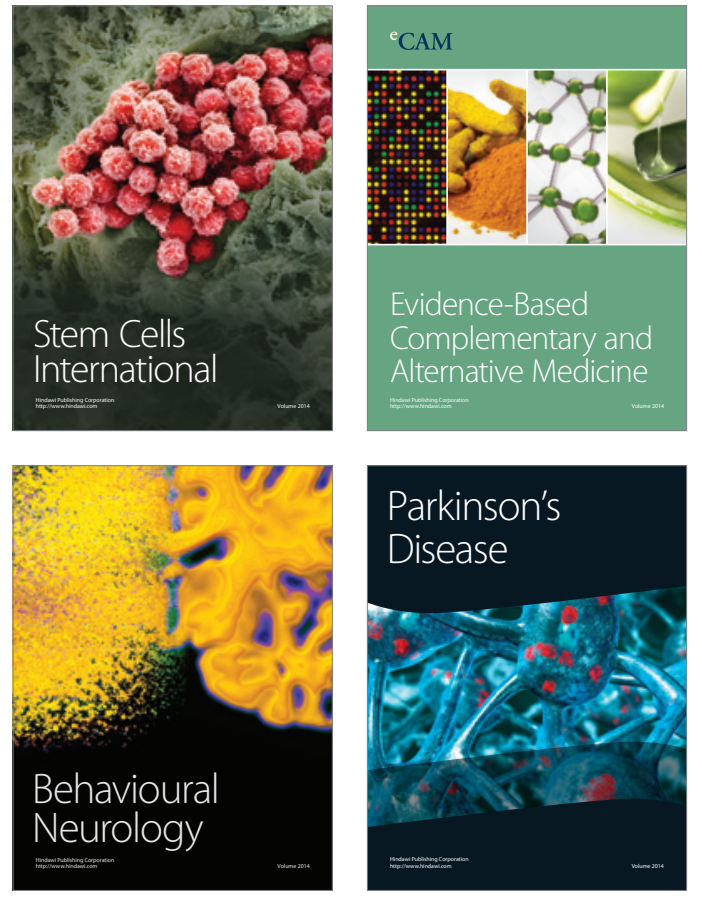
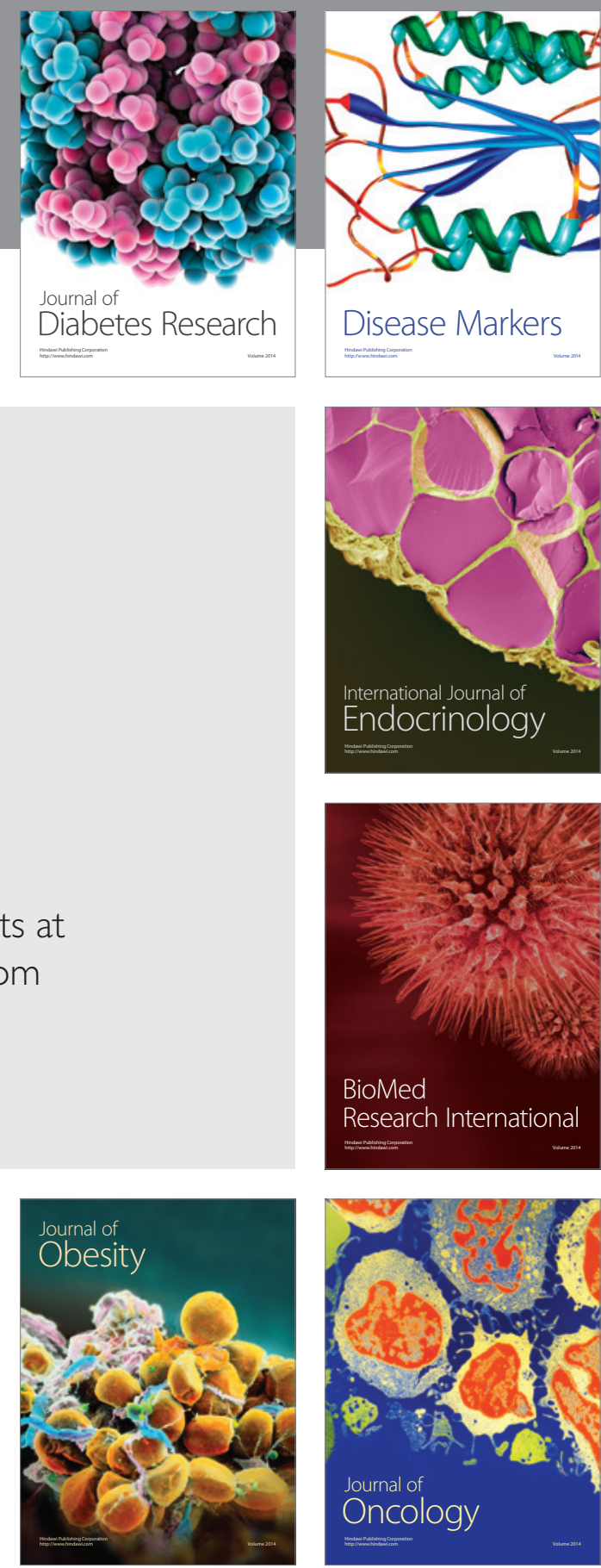

Disease Markers
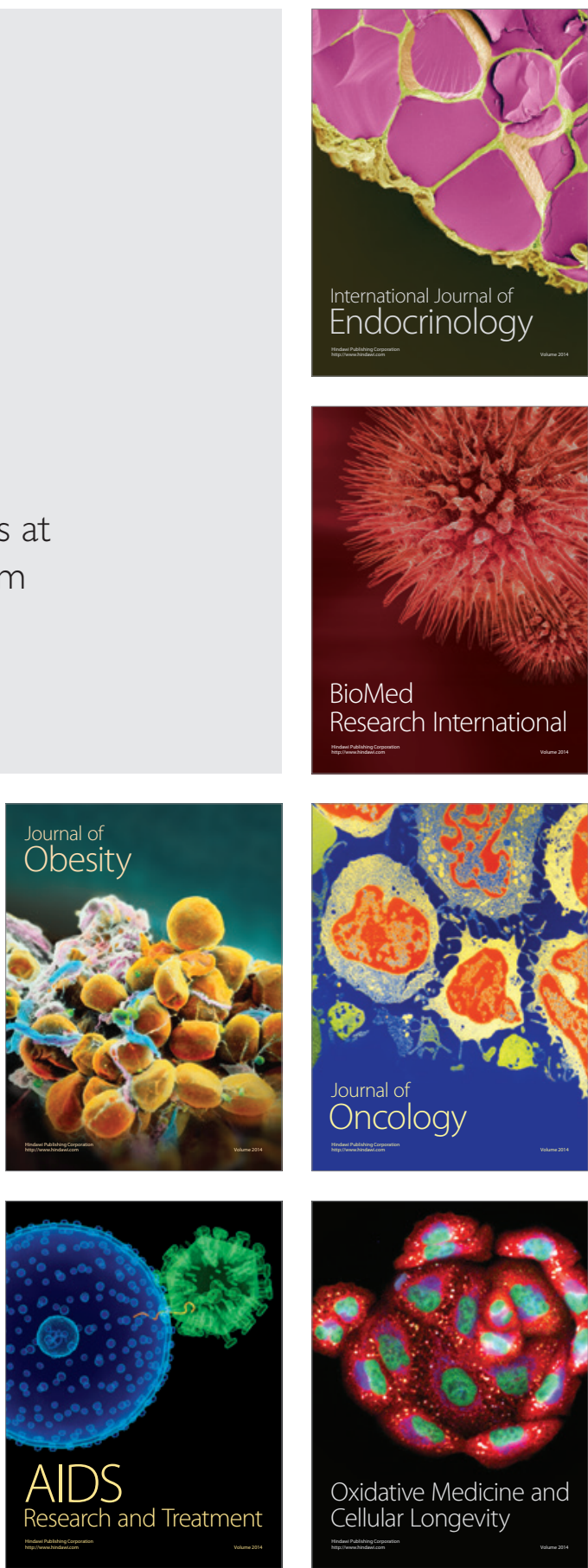